\title{
Defining Rural Smartness and Its Impact: A Systematic Literature Review
}

\author{
Iqbal Yulizar Mukti ${ }^{1}$ (D) - Maria E. Iacob ${ }^{1}$ - Adina Aldea ${ }^{1} \cdot$ Rajesri Govindaraju ${ }^{2}$. \\ Jos van Hillegersberg ${ }^{1}$
}

Received: 11 June 2020 / Accepted: 19 January 2021 / Published online: 25 February 2021

(c) The Author(s) 2021

\begin{abstract}
The utilisation of information technology to facilitate "smartness" is considered as a promising approach to improve the rural economy. However, the explanation of how the adoption of smartness in rural areas can lead to an improvement in the citizen's economic welfare is still lacking in current studies. This paper aims to formulate a theoretical model that explains the causal mechanism of smartness adoption in rural areas to contribute to the improvement of rural citizen's economic welfare. To achieve this, we conducted a systematic literature review based on three research questions resulting in 119 selected articles, which we used to formulate a theoretical model. The proposed model posits that rural smartness has a mediating effect on the citizen's economic welfare through its positive impact on the competitiveness and innovativeness of rural business entities. Additionally, the proposed theoretical model highlights the necessity of adopting a smart service platform, representing the IT artefact for smartness. We argue that the adoption of such a platform would have a significant moderating effect on the competitiveness and innovativeness of rural business entities. We also contribute a comprehensive set of candidate measures we extracted from the selected literature as operationalisation of the proposed model. In terms of contribution to practice, the proposed theoretical model can be used as the starting point to guide the diffusion of smartness in rural areas.
\end{abstract}

Keywords Rural smartness $\cdot$ Economic welfare $\cdot$ Theoretical model $\cdot$ Service platform $\cdot$ Systematic literature review

Iqbal Yulizar Mukti

i.y.mukti@utwente.nl

1 Department of Industrial Engineering and Business Information Systems, University of Twente, Enschede, The Netherlands

2 Faculty of Industrial Technology, Insitut Teknologi Bandung, Bandung, Indonesia 


\section{Introduction}

According to the United Nations (2018), most of the world's population is living in urban areas. However, the projections for 2030 indicate that almost half of the population in developing countries is expected to live in rural areas (Roland Berger, 2017). Using data from the World Bank for 89 developing countries, Castañeda et al. (2018) found that around $75 \%$ of those living on less than $\$ 3.1$ per day are people who live in rural areas. To escape the poverty trap, and motivated by a higher potential income, people from rural areas are migrating to urban areas (Sicular et al., 2007; Østby, 2016; De Magalhães and SantaeulàliaLlopis, 2018). Nevertheless, this is not a solution for the poverty problem, as shown in the study by Imai et al. (2017), which argue that rural-urban migration is not reducing, but increasing poverty. This phenomenon can be explained by the fact that a large proportion of people migrating from rural to urban areas end up working in low-skilled jobs for low wages (Zhang, 2016), while the living costs are significantly higher. Therefore, instead of encouraging urbanisation, efforts in developing the rural economy are more effective in reducing poverty (Imai et al., 2017).

In line with the advances of information technology (IT), one of the promising approaches to develop the rural economy is to make the rural areas smarter (Zavratnik et al., 2018). While the definition of smartness for rural areas is vague, and just starting to gain some attention in literature (Zavratnik et al., 2018; Mishbah et al., 2018), the concept of smartness for urban areas is already well established. Albino et al. (2015) provide a reference to the definition of smartness in urban areas that we summarised into the following: utilisation of information technology in hard domains (e.g. buildings, environment, mobility infrastructure, and logistics infrastructure) and soft domains (e.g. education, innovation, culture, and government) in an integrated manner that contributes to the improvement of citizen's living quality. Based on this reference, we define smartness as the utilisation of IT in an integrated manner to improve the living quality of the citizens. With this definition, our paper studies the adoption of smartness in rural areas, in particular with the aim to improve the citizen's economic welfare in an effort to reduce poverty.

There is a difference in focus between the adoption of smartness in urban and rural areas. In the urban context, the objective is generally to handle the typical problems of densely populated areas. For example, traffic and mobility, waste management, pollution, energy supply, or social issues (Angelidou, 2017; Neirotti et al., 2014). However, in the rural context, the objective is strongly centred around the empowerment of citizens and the development of the regional economic potential. The main assumption is that fostering IT innovation will lead to the emergence of a better local micro-economic climate (Zavratnik et al., 2018; Mishbah et al., 2018; Katara, 2016; Martinez-Gil et al., 2019).

Academics are showing their interest in the research related to the adoption of smartness to improve the economic situation for people living in rural areas. Previous studies have discussed the case of IT utilisation in rural 
economy activities (Santhiyakumari et al., 2016; S. Yu, 2017; Gyeltshen and Osathanunkul, 2018), the formulation of a strategy to implement smartness in a rural context (Naldi et al., 2015; Zavratnik et al., 2018), and the development of a framework for smartness adoption in rural areas (Mishbah et al., 2018; Katara, 2016; Talbot, 2016). However, the causal mechanism of how smartness adoption leads to economic welfare improvement is still missing in previous studies. Thus, to fill this gap, this paper has as a main objective the formulation of a theoretical model that explains the mechanisms through which the adoption of smartness is contributing to the achievement of economic welfare improvement for people living in rural areas.

To achieve this objective, this paper systematically identifies (1) the characteristics of smartness that have been mentioned in literature as having an economic impact, (2) the challenges that might constitute barriers for the adoption of smartness in the rural context, and (3) the functional characteristics of an IT artefact that facilitates the rural smartness implementation and acts as vehicle for the improvement of economic welfare for citizens in rural areas. We utilised systematic literature review (SLR) as the methodology guiding our research, which is further explained in the "Research Method" section. This methodology allows us to have a longitudinal analysis of the current academic literature, and to consolidate relevant information on this topic (Lagorio et al., 2016).

The contribution of this paper is twofold. First, this paper proposes a theoretical model that explains the causal mechanisms of smartness adoption in rural areas, which is hypothesised to have a positive impact on the improvement of citizen's economic welfare. Next to the model itself, an important contribution of this work is the rigorous definition of the concept of rural smartness which is defined both semantically as the situation when the implementation of IT infrastructure and services can empower the citizens to improve their living quality and welfare through connectivity and participatory governance, and operationally though a comprehensive set of candidate measures extracted from the literature. Hence, the proposed model and its operationalisation can become the starting point for further empirical research on this topic.

Secondly, this paper provides practical guidance for the implementation of rural smartness. For example, the readiness factors presented in the theoretical model can help the local government to assess and take necessary measures to stimulate the adoption and development of smartness in rural areas, with the aim of reducing the poverty. Moreover, the main functional characteristics of smartness presented in the theoretical model can be translated into a preliminary set of functional requirements guiding the design of an IT smartness service platform tailored for the rural context.

The remainder of this paper is structured as follows: the "Related Work" section describes the related work in the area of rural smartness. The "Research Method" section explains our approach to the SLR based on the selected research methodology. The "Results" section presents the results from the SLR. The "Discussion" section discusses the development of the theoretical model based on the results presented in the "Results" section. Finally, the "Conclusion" section provides the conclusion of this study and gives pointers to future work. 


\section{Related Work}

Research on the adoption of smartness technology in rural areas is recently gaining attention from academics. Several authors conducted case studies on the utilisation of IT to improve the economic situation for citizens in rural areas. For example, utilisation of IT equipment to increase the productivity of farmers (Santhiyakumari et al., 2016), development of a financing platform for rural SMEs (Yu, 2017), and the development of a platform to market agricultural products (Gyeltshen and Osathanunkul, 2018).

Other authors conducted studies that put more emphasis on the formulation of strategies to successfully implement smartness technology in the rural context. Naldi et al. (2015) examined strategies to achieve economic growth in the rural areas of Europe. In this regard, the authors suggest that the utilisation of IT in rural areas should support the development of local creative economies, optimise the potential of local amenities (e.g. natural amenities, recreational sites, and local culture), and strengthen the connectivity with related parties in the region for collaboration. Zavratnik et al. (2018) examined several smart villages initiatives worldwide. Their analysis resulted in the following strategies to develop the rural economy through the adoption of smartness technology. First, finding local solutions according to the unique potentials in particular rural areas. Second, exploring linkages with small towns or cities. Third, directing economic activities into the low-carbon circular economy. Fourth, promoting digital transformation.

Other studies are aimed at developing a framework to classify essential elements of rural smartness. Katara (2016) studied the adoption of smart villages in India. The author proposed a framework consisting of necessary components for the realisation of rural smartness, namely, (1) an economic component (e.g. entrepreneurship and governance model), (2) an environmental component (e.g. environmental infrastructure and natural products), (3) a social component (e.g. citizens participatory and culture), and (4) capacity building (e.g. personality development and community development). Mishbah et al. (2018) investigated academic literature with regards to smart villages. Based on a systematic literature review, the authors proposed a framework consisting of four main components for rural smartness: objectives, strategies, dimensions, and foundations. Mishbah et al. (2018) suggest, to achieve the objective in developing rural economies, strategies that lead to innovation through the utilisation of ICT need to be defined in seven dimensions: economy, IT, people, governance, environment, living, and energy. Furthermore, to be able to execute the strategies, several foundational elements (e.g. amenities, IT infrastructure, and human resources) according to specific characteristics of a rural area need to be prepared.

In terms of IT artefacts for rural smartness, Talbot (2016) developed a model that connects the policymakers and the entrepreneurs to boost innovation for economic growth in rural areas. The key feature in the model is the establishment of a network-based innovation brokerage (NBIB) as a service platform. This should facilitate collaboration between diverse business entities, independent of their geographical location, to optimise their existing potential and promote 
innovation-based value creation. Talbot (2016) validated the model through a case study in the rural region of Scotland. The results of the case study confirmed that utilisation of the service platform can facilitate the innovation process which is the driver for economic development in rural areas.

Furthermore, Mukti (2019) proposed a framework to improve the economic welfare of rural citizens through the utilisation of a service platform as the IT artefact for rural smartness. The framework suggests that the introduction of a service platform relies on technological readiness (e.g. connectivity and availability of devices), organisational readiness (e.g. government support and sustainable funding) and environmental readiness (e.g. citizen's digital capability and supportive regulatory).

The aforementioned studies all suggest that the adoption of smartness in rural areas can have a positive contribution to the rural economy. However, the explanation of how smartness adoption in rural areas can lead to improved citizen's economic situation is still missing. Therefore, this paper formulates a theoretical model that explains the causal mechanisms of smartness adoption in rural areas as a means to improve citizens' economic welfare.

\section{Research Method}

For this study, we had to adopt a literature review methodology that can support us to comprehensively analyse the extant literature to the extent that the objectives mentioned in the "Introduction" section are achievable. According to our analysis on the topology of literature review methodologies identified by Hood and Wilson (2001), Grant and Booth (2009), Paré et al. (2015), and Samnani et al. (2017), the methodologies to review the extant literature can be divided into two categories:

- Content-based methodologies, in which the focus is on in-depth analysis of the literature content with the goal of advancing the knowledge of a particular topic of interest. Methodologies falling into this category are including narrative review, critical review, SLR, mapping review, and umbrella review.

- Metric-based methodologies, which focus on the statistical analysis of quantitative metrics of the literature (e.g. number of citations and number of keywords) to understand the dynamics of a particular research field. Methodologies falling into this category are including descriptive review, quantitative meta-analysis, bibliometrics, and scientometrics.

Among the methodologies mentioned in the two above categories, we argue that SLR is the most suitable methodology to achieve the objective of this paper. The reason is because SLR comes with a very clear standard scientific protocol to select and critically analyse the content of the extant literature to answer the proposed research questions that will further be described in the "SLR Research Questions" section (Kitchenham and Charters, 2007; Samnani et al., 2017; Linnenluecke et al., 2020). Furthermore, as justified by Shaffril et al. (2020), the SLR method 


\begin{tabular}{|c|c|c|c|}
\hline \multicolumn{2}{|c|}{ Research Design } \\
\hline Define RQs & Select scientific databases & Formulate search query for each & $\begin{array}{c}\text { Define inclusion and exclusion } \\
\text { criteria }\end{array}$ \\
\hline
\end{tabular}

\begin{tabular}{|c|c|c|c|c|}
\hline \multicolumn{3}{|c|}{ Selection } \\
\hline $\begin{array}{c}\text { Article selection to each } \\
\text { query results by inclusion } \\
\text { criteria }\end{array}$ & $\begin{array}{c}\text { Remove duplicate studies } \\
\text { in each } R Q \text { and exclusion } \\
\text { of irrelevant articles based } \\
\text { on title and abstract } \\
\text { assessment }\end{array}$ & $\begin{array}{c}\text { Exclusion based on full } \\
\text { text availability }\end{array}$ & $\begin{array}{c}\text { Exclusion of irrelevant } \\
\text { articles based on full text } \\
\text { assessment }\end{array}$ & $\begin{array}{c}\text { Remove duplicate articles } \\
\text { across RQs results }\end{array}$ \\
\hline
\end{tabular}

$\sqrt{3}$

\begin{tabular}{|l|c|c|}
\hline \multicolumn{2}{|c|}{ Synthesise } \\
\hline Data extraction according to each RQ & Report findings on each RQ & $\begin{array}{c}\text { Theoretical model formulation based on } \\
\text { findings }\end{array}$ \\
\hline
\end{tabular}

Fig. 1 SLR activities

provided us guidance to execute the literature study in an organised, transparent, and replicable manner.

This paper follows the SLR methodology proposed by Rouhani et al. (2015) and Kitchenham and Charters (2007). The argument for this SLR variant is that it has been specifically designed for literature research in the information system field, to which this work clearly belongs. Figure 1 presents all the SLR activities performed in this paper that are grouped into three phases. We describe these phases in more detail in the following sub-sections.

\section{Research Design}

This phase defines several requirements to ensure that the article selection process will meet the research objectives. These requirements include the definition of SLR research questions (RQ), scientific databases for article selection, search query for each RQ, and inclusion and exclusion criteria.

\section{SLR Research Questions}

Defining the RQs is an essential step in the SLR since it drives the entire review process (Kitchenham and Charters, 2007). In our research, we defined three RQs that contribute to the development of the theoretical model. Figure 2 presents a summary of the RQs and their contributions to the theoretical model.

RQ1: What are the contributions of smartness to the economic welfare of the citizens?

Our goal with this question is to identify the characteristics of smartness that have been mentioned in literature to have an economic impact, and the performance indicators used to measure that impact. Answering this question will contribute to 


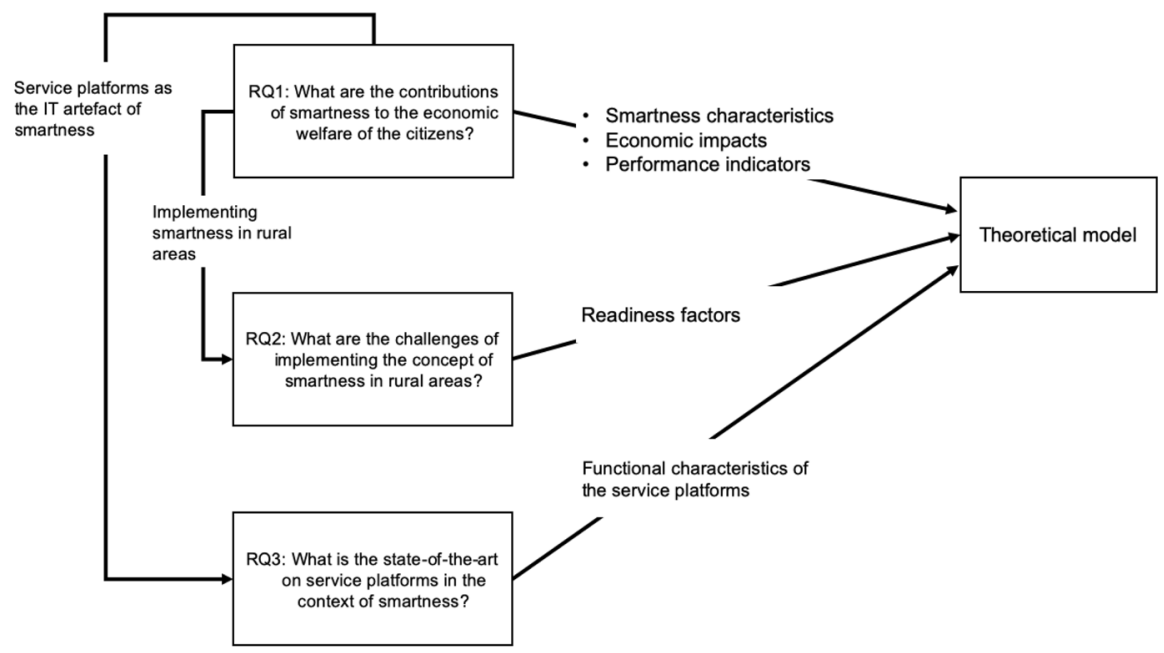

Fig. 2 Relationship between RQs and theoretical model

the theoretical model development, particularly in selecting those elements that can be seen as antecedents of citizens' economic welfare improvement.

RQ2: What are the challenges of implementing the concept of smartness in rural areas?

This question will require the identification of challenges that might raise barriers for the adoption of smartness in the rural context. Answering this question will help us identify those elements of the theoretical model that represent readiness factors, and need to be in place for the successful adoption of smartness in rural areas.

RQ3: What is the state-of-the-art on service platforms in the context of smartness?

There is a growing interest in implementing service platforms as the IT artefact that can help to improve the economic welfare of citizens in rural and urban areas. Talbot (2016) found that service platforms facilitate the collaboration between business entities in rural areas, and connect them to the larger networks. Thus, this medium enables entrepreneurs in rural areas to become aware of, and to exploit new economic opportunities. Furthermore, Lusch and Nambisan (2015) suggest that a service platform is a suitable IT artefact to exchange or share resources, and co-create value.

To answer this question, we explore the current developments concerning service platforms as the IT artefact of smartness. This will require the identification of the state-of-the-art functional characteristics, the technology used, and the stakeholders involved in such platforms. This helps us identify the functional characteristics of the service platform that have a significant moderating effect on the citizen's economic welfare. Furthermore, insights gained from answering this question will constitute the foundation for the architectural design process of the service platform tailored to improve the rural economy. 


\section{Scientific Databases}

To obtain relevant academic publications for answering the research objectives, this SLR used scientific databases as the source to perform the article selection process. The main reason for this is that scientific databases aggregate articles from relevant academic sources such as journals, conference proceedings, and book series. The following are the scientific databases selected for our SLR:

- Scopus (http://www.scopus.com/)

- Web of Science (WoS) (http://www.webofknowledge.com/)

- IEEE Xplore (http://ieeexplore.ieee.org/)

We chose these databases since they provide a good coverage of the existing academic literature and they lead to the highest number of relevant results. For example, searches using keywords related to urban smartness ("urban smartness" OR "city smartness" OR "smart urban" OR "smart city" OR "smart cities" OR "digital city" OR "digital cities") resulted in 20,612 results in Scopus, 10,413 results in WoS, and 11,596 results in IEEE Xplore. Moreover, these databases provide easy to use search engines that enable query-based searching with logical operators (e.g. AND and OR), facilitate filtering to limit the selection of the articles based on pre-defined criteria (e.g. year, topics, language, and type of publications), and allow to export the lists of results to reference management tools, such as EndNote.

\section{Search Query Design}

The search query is constructed based on a set of (synonymous) keywords related to a particular research question, which are combined with logical operators. The search query is applied to the article's title, abstract, and keywords.

Search Query for RQ1 The objective of this search query is to retrieve articles that describe the characteristics of the smartness and their contributions to the citizen's economic welfare. To achieve this objective, we used the sets of relevant synonymous keywords presented in Table 1. In the first and the second column, we used

Table 1 Synonymous keywords for RQ1

\begin{tabular}{lllll}
\hline Urban smartness & Rural smartness & Characteristic & Economy & Contribution \\
\hline Urban smartness & Rural smartness & Characteristic & Economy & Effect \\
City smartness & Smart rural & Component & Economic & Impact \\
Smart urban & Smart village & Factor & Welfare & Benefit \\
Smart city & Village smartness & Element & Business & Influence \\
Smart cities & Digital rural & Predictor & Entrepreneurship & Opportunit* \\
Digital city & Digital village & & & Indicator \\
Digital cities & Digital inclusion & & & Performance \\
& & & & Measurement \\
\hline
\end{tabular}


synonymous keywords related to the adoption of smartness in urban and rural areas. In the third to the fifth column, we used the synonymous keywords that can help us identify those characteristics of smartness that have been mentioned in the literature as having an economic contribution, including the relevant performance indicators.

To construct the search query, the keywords within each column are combined using the "OR" operator, while between columns we use the "AND" operator. This approach resulted in the following search query:

("urban smartness" OR "city smartness" OR "smart urban" OR "smart city" OR "smart cities" OR "digital city" OR "digital cities" OR "smart rural” OR "rural smartness" OR "smart village" OR "village smartness" OR "digital rural" OR “digital village” OR “digital inclusion").

AND (factor OR component OR element OR predictor OR characteristic)

AND (economy OR economic OR welfare OR business OR entrepreneurship)

AND (impact OR effect OR influence OR benefit OR opportunit* OR indicator OR performance OR measurement).

Search Query for RQ2 The objective of this search query is to retrieve articles that describe the challenges during the adoption and diffusion of smartness technology in rural areas. The sets of relevant synonymous keywords used to construct this search query are presented in Table 2. Since the concept of smartness for urban areas is already well established, we used synonymous keywords related to urban smartness (column 1) merged with synonymous keywords that represent the rural area (column 2) to direct the results into the adoption of urban smartness within the rural context. In column 3, we used synonymous keywords related to rural smartness to focus on the adoption of smartness in rural areas. In the last column, we used synonymous keywords that will help us identify the challenges of smartness adoption in the rural context.

Similarly to the previous research question we used logical operators to construct the following search query:

((("urban smartness" OR "city smartness" OR "smart urban" OR "smart city" OR "smart cities" OR “digital city" OR "digital cities") AND ( rural OR village OR region))

OR ("smart rural" OR "rural smartness" OR "smart village" OR "village smartness" OR "digital rural" OR "digital village" OR "digital inclusion"))

AND (challenge OR difficulty OR difficulties OR impediment OR barrier).

Table 2 Synonymous keywords for RQ2

\begin{tabular}{llll}
\hline Urban smartness & Rural context & Rural smartness & Challenges \\
\hline Urban smartness & Rural & Smart rural & Challenge \\
City smartness & Village & Rural smartness & Difficulty \\
Smart urban & Region & Smart village & Difficulties \\
Smart city & & Village smartness & Impediment \\
Smart cities & & Digital rural & Barrier \\
Digital city & & Digital village & \\
Digital cities & & Digital inclusion & \\
\hline
\end{tabular}


Table 3 Synonymous keywords for RQ3

\begin{tabular}{llll}
\hline Urban smartness & Rural smartness & Platform & Government \\
\hline Urban smartness & Smart rural & Platform & Government \\
City smartness & Rural smartness & Service platform & Local government \\
Smart urban & Smart village & e-government & Municipality \\
Smart city & Village smartness & Open data & Municipalities \\
Smart cities & Digital rural & Government as a platform & \\
Digital city & Digital village & & \\
Digital cities & Digital inclusion & & \\
\hline
\end{tabular}

Search Query for RQ3 The objective of this search query is to retrieve articles that describe the current developments and trends on service platforms in the context of urban and rural smartness. For this purpose, we used the sets of relevant synonymous keywords presented in Table 3 . In the first and the second column, we used synonymous keywords related to urban and rural smartness, since the service platform should be applicable in the context of smartness. In the third and fourth column, we used synonymous keywords to extract search results that focus on service platforms initiated by the government. We emphasise the role of government in the provision of the service platform since the investment in smartness for rural areas is not economically attractive for private companies (Philip and Williams, 2019; Roberts et al., 2017; Correa and Pavez, 2016).

The search query we used for the last research question is shown below:

("urban smartness" OR "city smartness" OR "smart urban" OR "smart city" OR "smart cities" OR "digital city" OR "digital cities" OR "smart rural" OR "rural smartness" OR "smart village" OR "village smartness" OR "digital rural" OR "digital village" OR "digital inclusion").

AND (platform OR "service platform" OR "e-government" OR "open data" OR "government as a platform")

AND (government OR "local government" OR municipality OR municipalities).

\section{Inclusion and Exclusion Criteria}

Inclusion and exclusion criteria are defined to identify primary articles that provide direct evidence for the research question (Kitchenham and Charters, 2007). In this phase, we selected articles that meet the inclusion criteria. Then we removed articles according to the exclusion criteria by evaluating their title, abstract, and full text. Table 4 shows the inclusion and exclusion criteria used in this study.

Concerning the inclusion criteria, we only include the articles that are written in English. This is because most of the search results related to the RQs are written in English (more than 98\% in Scopus and WoS). Second, we only considered articles published in journals and conference proceedings. The reason for this is that journals and conference proceedings usually go through a thorough peer-review process to ensure the quality of published articles. Third, to help retrieve relevant articles, we only included those in the subject areas related to the RQs: engineering, computer science, social sciences, decision 
Table 4 Inclusion and exclusion criteria

Inclusion criteria

Articles written in English

Articles published in Journals or Conference Proceedings

Subject areas of the articles are in the field of engineering, computer science, social sciences, decision science, business management, and economics.
Exclusion criteria

Duplicate articles (by title or content)

Articles not related to the RQ (by title, abstract, and full text)

Articles published from 2011

science, business management, and economics. Fourth, regarding the publishing period, we only selected articles published from 2011. The reason for this decision is based on a study conducted by Cocchia (2014), in which it is mentioned that research related to urban smartness shows significant growth from 2011 on. Scopus search results also justified this trend. As shown in Fig. 3, there is a significant growth in publications on the topic of urban smartness from 2011 on.

On the other hand, as result of applying the exclusion criteria, we remove duplicate articles and the articles that have no relation with each RQ. For RQ1, these articles do not describe any characteristics of smartness and its contribution to economic welfare improvement. For RQ2, these articles do not explain any challenges in implementing smartness in rural areas. Lastly, for RQ3, these articles have no relation with service platforms in the context of smartness.

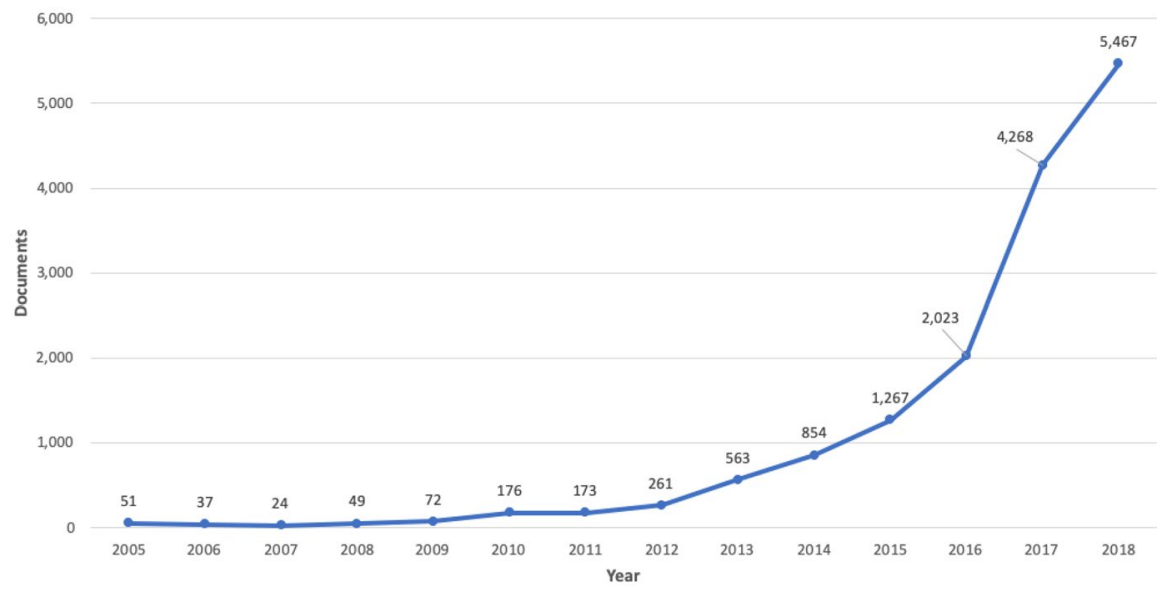

Fig. 3 Scopus search result on query related to urban smartness: TITLE-ABS-KEY ("urban smartness" OR "city smartness" OR "smart urban" OR "smart city” OR "smart cities" OR "digital city" OR "digital cities") 


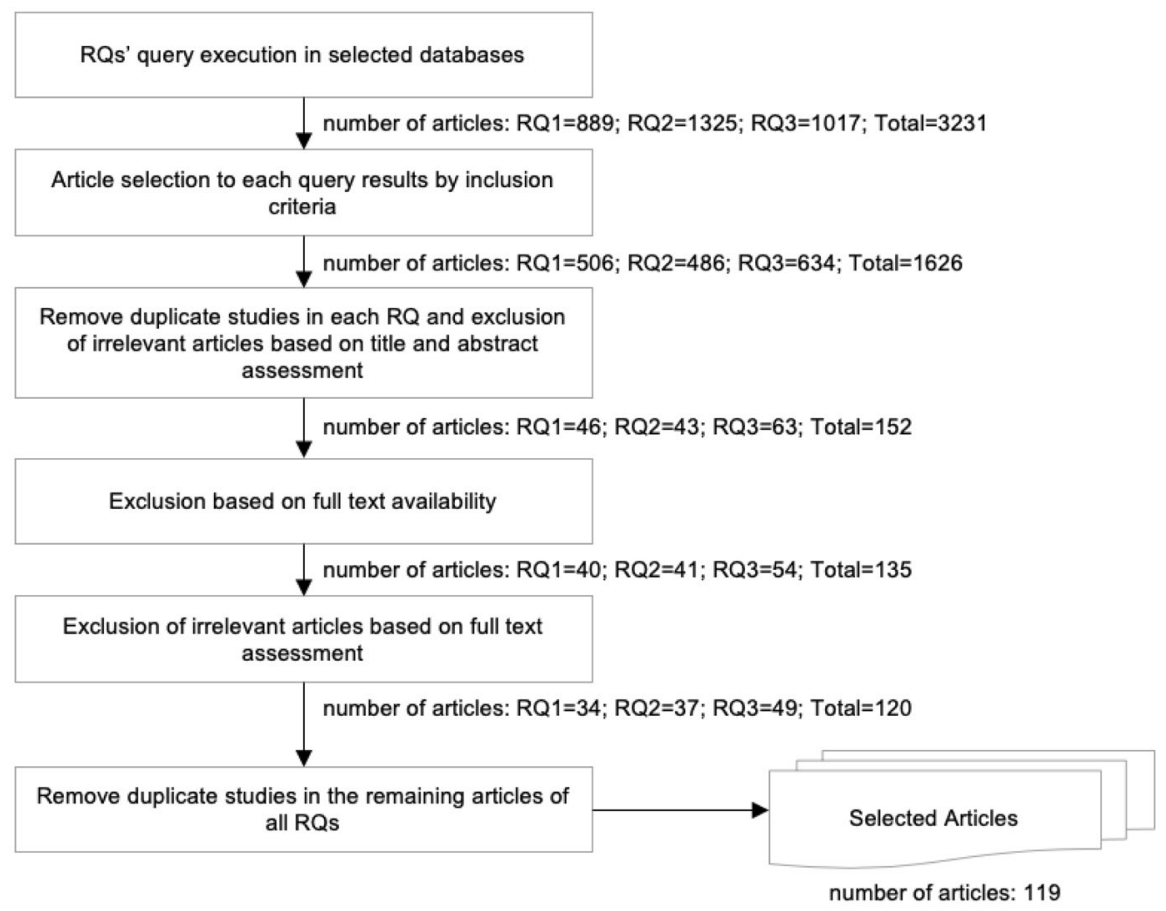

Fig. 4 Article selection process

\section{Selection Process}

There are six steps taken in the selection process phase to obtain the primary articles for this study. Figure 4 shows a diagram of these steps, along with the number of selected articles in each step. First, we executed the search query for each RQ in the selected academic databases (Scopus, Web of Sciences, and IEEE Xplore) in July 2019. Second, we refined the search results by applying the inclusion criteria using the filters provided in the academic databases. We exported the search results to EndNote since it is easier to categories the references, to find and delete duplicate references, to assess the reference information (e.g. title, abstract, keywords, year of publication, type of publication, and name of publication), and it has a built-in tool to download the full text of the reference. Furthermore, using EndNote, for each RQ, we consolidated the references retrieved from the three databases by removing the duplicate references and retaining the unique references.

In the third step, we removed irrelevant articles in each RQ by reviewing the title and abstract and based on further analysis according to the exclusion criteria. Fourth, we deleted the articles for which we could not download the full text. Fifth, we removed irrelevant articles through the assessment of the full text according to the exclusion criteria. At this point, we collected 120 articles for all RQs. However, in the last step, we found an article that is relevant for both 
RQ1 and RQ3. Considering this duplication, the number of selected articles is 119 (see Appendix). Please note that we use the unique article ID included in the Appendix when we refer to a specific article in a table to present the literature analysis results in a more compact manner. Nevertheless, when we discuss an article in the text we refer to it using a usual citation.

\section{Synthesis}

To properly synthesise the primary articles, we collected relevant information based on the data extraction form shown in Table 5. We used the extracted information to carry out both a quantitative and qualitative synthesis. We performed the quantitative synthesis based on bibliographic reference and the qualitative synthesis based on the thematic analysis according to the data items relevant to the RQs, as is presented in the "Results" section. Furthermore, based on the results of our synthesis, we formulate the theoretical model that will be discussed in the "Discussion" section.

\section{Results}

In this section, we present the results of the SLR based on the information we collected and synthesised using the data extraction form. The bar chart in Fig. 5 illustrates the number of articles based on publication type, grouped by RQ. As shown in the chart, the number of selected articles for RQ1 and RQ3 are published almost equally in journals and conference proceedings. This result indicates that the topic covered in RQ1 (contributions of smartness to the economic welfare) and RQ3 (state-of-the-art on service platforms) has a higher level of maturity since articles published in a journal, in most cases, go through a more rigorous peer-review process and contain more elaborate research. In the case of RQ2, the majority of articles are published in conference proceedings and has the highest number of conference proceedings articles among other RQs. This result indicates that the topic covered in RQ2 (adoption of smartness in rural areas) is still in the early stage of development.

When it comes to the source of the selected articles, in Fig. 6, we can see that all the scientific databases contributed as sources of the selected articles. Scopus dominated as the main source of literature in all RQs, IEEE results give a significant contribution to the selected articles in RQ2, and WoS contributed to the majority of articles in RQ3.

Figure 7 shows the histogram of publications between 2011 and (July) 2019. Note that the majority of the selected articles are published in the last four years (73\%). This suggests that there is a growing interest among researchers for the topics covered by all RQs, with a sudden surge in 2018 of research on topics related to the adoption of smartness in rural areas (RQ2) and the utilisation of service platforms as the IT artefact of smartness (RQ3).

To gain insight in the relationship between the authors of the selected articles, in Fig. 8, we plot countries of the first authors' affiliation against the selected 
Table 5 Data extraction form

\begin{tabular}{|c|c|c|c|}
\hline No. & Extracted data & Data item & Relevance \\
\hline 1 & Bibliographic reference & $\begin{array}{l}\text { Authors, year of publication, title, source of } \\
\text { publication, source of database, and type of } \\
\text { publication }\end{array}$ & General \\
\hline 2 & $\begin{array}{l}\text { Contributions of smart- } \\
\text { ness to the economic } \\
\text { welfare }\end{array}$ & $\begin{array}{l}\text { Smartness characteristics contributed to the } \\
\text { improvement of economic welfare, economic } \\
\text { impacts of smartness, and performance indica- } \\
\text { tors that measured economic welfare improve- } \\
\text { ment caused by smartness }\end{array}$ & RQ1 \\
\hline 3 & $\begin{array}{l}\text { Challenges in imple- } \\
\text { menting the smart- } \\
\text { ness concept in rural } \\
\text { areas }\end{array}$ & $\begin{array}{l}\text { Challenges in three categories (technological, } \\
\text { organisational, and environmental) }\end{array}$ & RQ2 \\
\hline 4 & $\begin{array}{l}\text { State of the art of } \\
\text { service platform }\end{array}$ & $\begin{array}{l}\text { Functional characteristics, technology used, and } \\
\text { involved stakeholders service platforms }\end{array}$ & RQ3 \\
\hline
\end{tabular}

articles for each RQs. According to the United Nations (2020), countries in the bracket are developing countries, while the rest are developed countries. As it can be seen from the histogram, selected articles on the topic of RQ1 were written by authors from developed and developing countries with 15 and 19 articles, respectively. This finding suggests that research on the topic of the contributions of smartness to the economic welfare is commonly addressed by researchers, regardless of the country of origin classification. With regard to

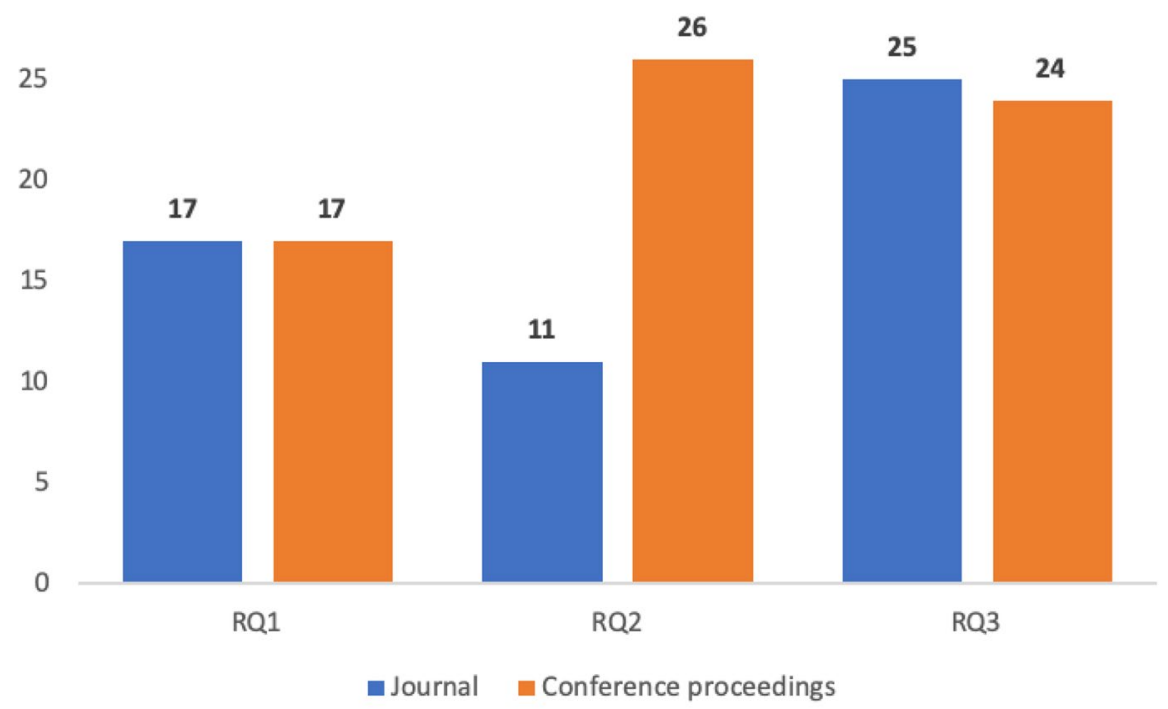

Fig. 5 Number of selected articles based on publication type 


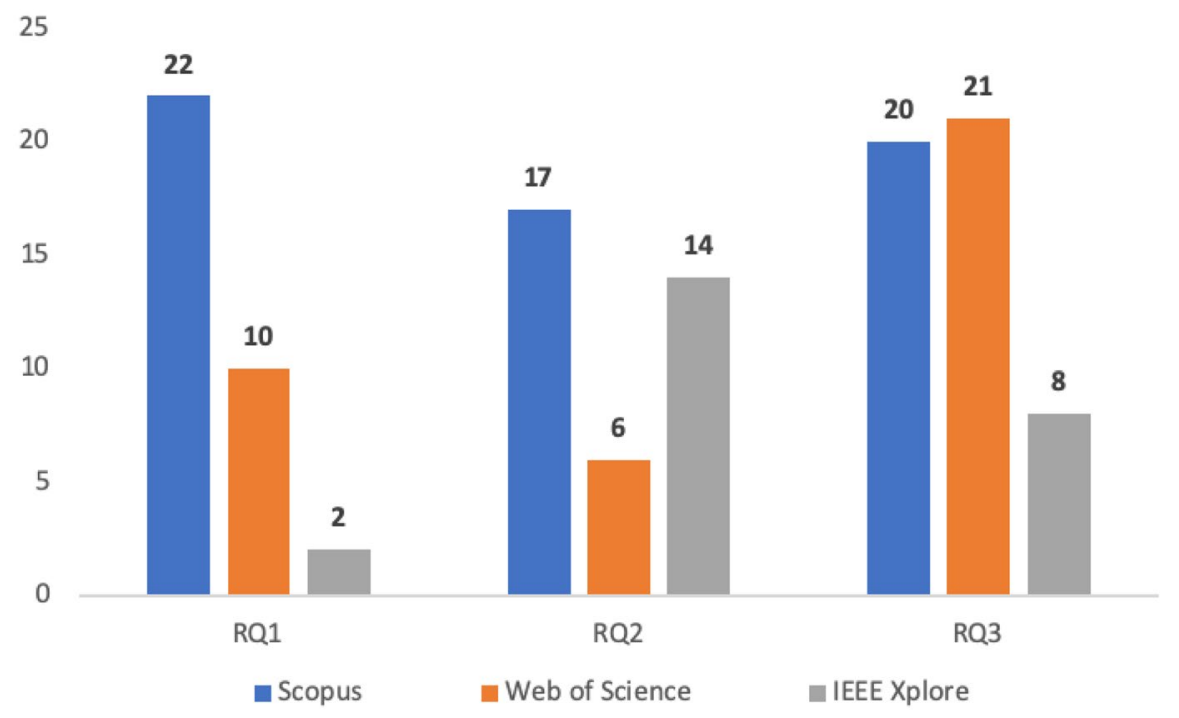

Fig. 6 Number of selected articles across scientific databases

the topic of RQ2, whilst there is no much difference between the total number of articles written by authors from developed and developing countries (18 and 19 articles, respectively), authors from India were dominating our selection with 11 articles. This finding indicates that the topic concerning the adoption of smartness into rural areas is gaining momentum in countries where the majority of the population is living in rural areas. On the other hand, most of the selected articles on the topic of RQ3 were written by authors from developed countries with 37 articles, which is significantly more than the number of contributions from developing countries with 12 articles. This result indicates that the research addressing state-of-the-art service platforms were mostly gaining attentions from the authors located the countries with a well-established IT infrastructures.

\section{Findings on RQ1}

The objective of RQ1 is to identify contributions of the smartness adoption to the improvement of citizen's economic welfare. To achieve the objective, based on the assessment of the selected articles, we identified several characteristics of smartness that contribute to the economic welfare improvement (Table 6), the economic impacts of smartness (Table 7), and the performance indicators to measure these impacts (Table 8).

In Table 6, we present four characteristics of smartness that contribute to the improvement of citizen's economic welfare. What is interesting in the results is that although the most cited characteristic is closely related with IT, the second and the third most cited characteristics are related to cooperation between 


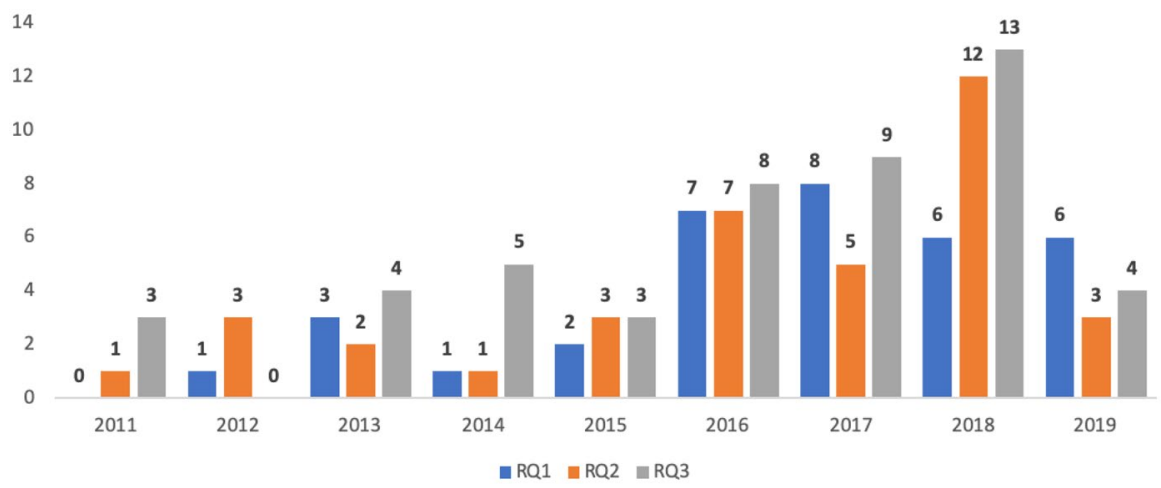

Fig. 7 Number of selected articles per year and RQ

involved stakeholders and the capabilities of the citizens. This finding shows that the concern relating to the smartness adoption is not merely about the use of IT, but also the orchestration of multiple stakeholders.

In Table 7 , we present seven main economic impacts of smartness adoption identified from the selected literature. The economic impacts mentioned in the table are relatively equally distributed over the selected articles which indicates that they are acknowledged by most authors as main consequences of smartness adoption. However, the facilitation of business collaboration has the highest number of supporting articles, which suggests that it is an essential factor.

In Table 8, we categorised relevant performance indicators to measure the economic impact of smartness adoption in four categories: productivity, welfare, innovation, and new business creation. The results indicate that the utilisation of smartness discussed in the selected articles is mainly aiming at improving the productivity of business activities. The utilisation of smartness as the enabler for innovation, especially to create new business, seems understudied.

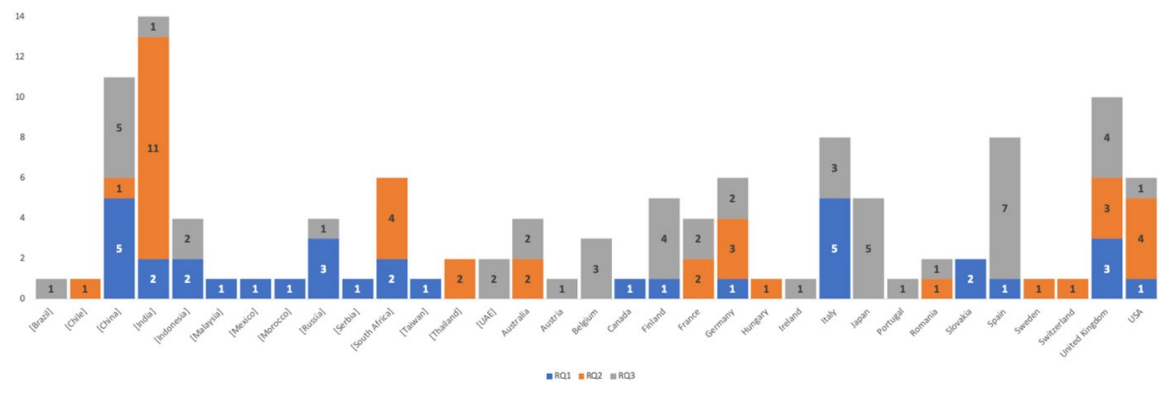

Fig. 8 Number of selected articles per country of the first author's affiliation location and RQ 


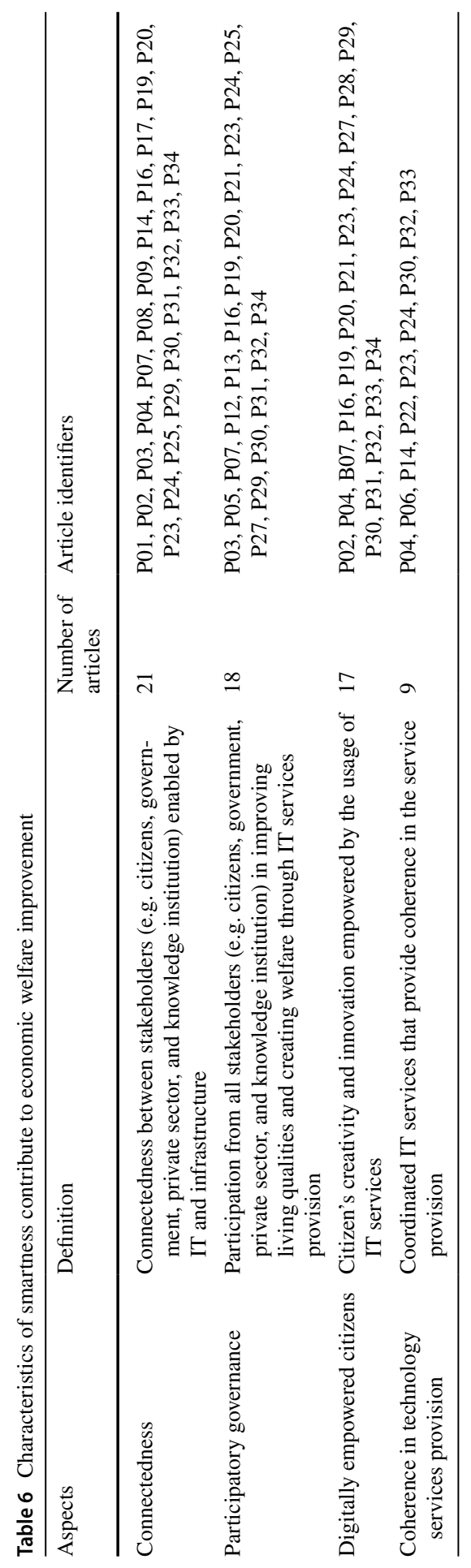




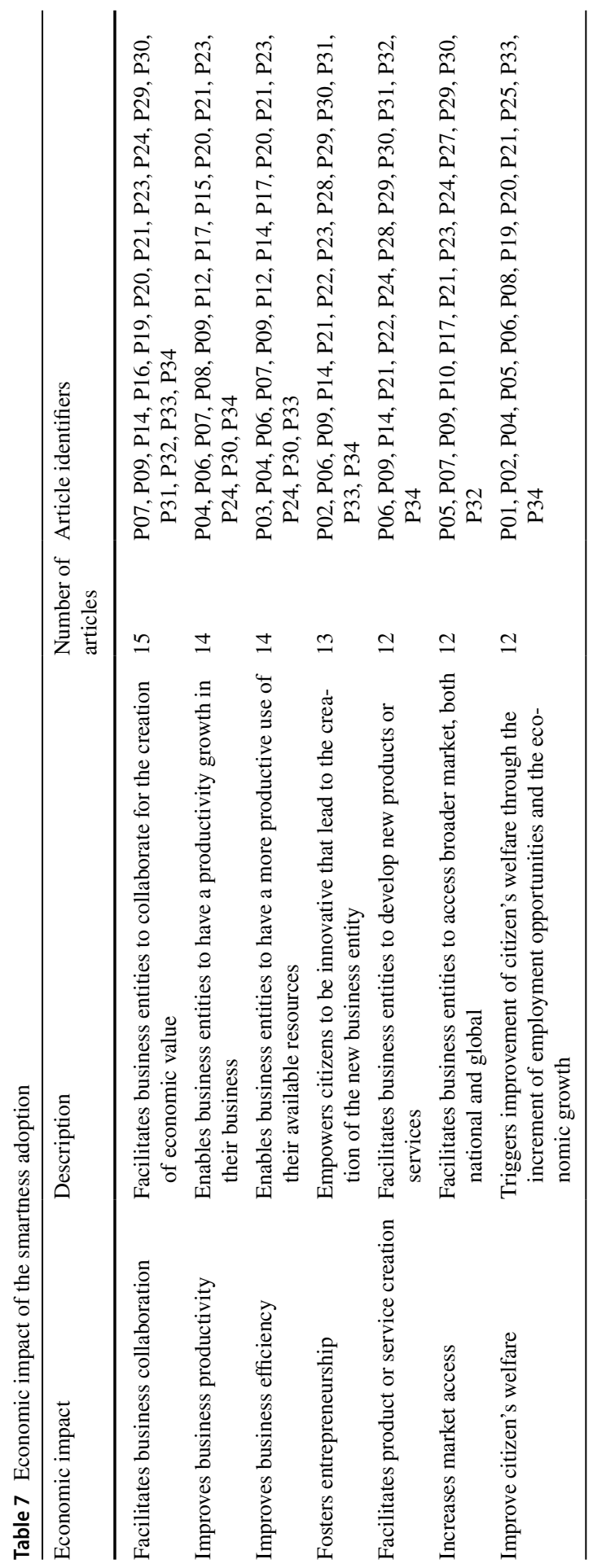




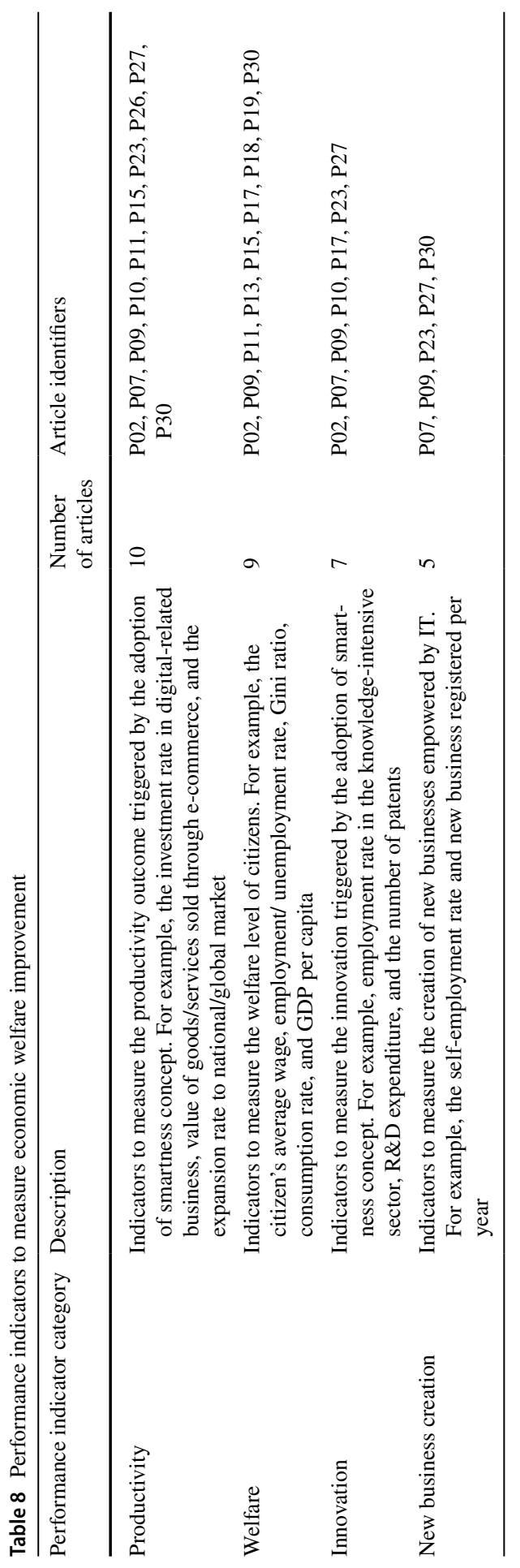




\section{Findings on RQ2}

The objective of RQ2 is to identify challenges that might raise barriers for the adoption of smartness in the rural context. To achieve the objective, we structured the challenges based on the technology-organisation-environment (TOE) framework by Tornatzky, Tornatzky and Fleischer (1990). According to this framework, three aspects influence the adoption of technological innovation, namely technological, organisational, and environmental. We consider the adoption of smartness in rural areas as a form of technological innovation adoption. Therefore, according to the TOE framework, we use the following three categories to group the challenges:

- Technological challenges are related to the quality and characteristics of technology that influence the adoption of smartness in rural areas.

- Organisational challenges are related to the characteristics and capability of the organisation responsible for managing the smartness initiatives in rural areas.

- Environmental challenges are related to the characteristics of involved stakeholders and regulatory environment that influence the adoption of smartness in rural areas.

Table 9 shows five technological challenges for the adoption of smartness in rural areas found in the selected articles. We found a significant gap between the frequency of the most mentioned technological challenge, i.e. broadband access implementation, and that of all other challenges. Also notable is the finding that only very few of the authors mention challenges related to strategic guidelines. This suggests that the main barrier for adopting smartness in rural areas is the lack of sufficient connectivity infrastructure as prerequisite of rural smartness.

Table 10 shows organisational challenges identified from the selected articles. Our assessment indicates that the main organisational bottlenecks for smartness adoption are related to the availability of sustainable funding, and organisational capabilities. This result suggests that the assurance of funding, and the capabilities of the organisation responsible for managing the smartness initiatives which are perceived as the two most important organisational aspects for the successful adoption of smartness in rural areas.

Table 11 presents the environmental challenges addressed by the selected articles. What stands out from the results is that most of the challenges are related to the citizen's capabilities, including, low level of digital knowledge, low purchasing power for digital infrastructure and services, resistance to change, and lack of entrepreneurial capabilities. These results suggest that the development of rural citizen's capabilities is a crucial aspect for the successful adoption of smartness in rural areas.

In order to make explicit the relation between a regional characteristics and specific types of challenges in adopting smartness in rural areas, in Fig. 9, we map them against the location of the study (horizontal axis). The number in the grid represents the number of articles that cite a specific challenge carried out in a particular location. We used the term "generic" for studies where the authors did not mention any specific location. As it can be seen in Fig. 9, the studies from 


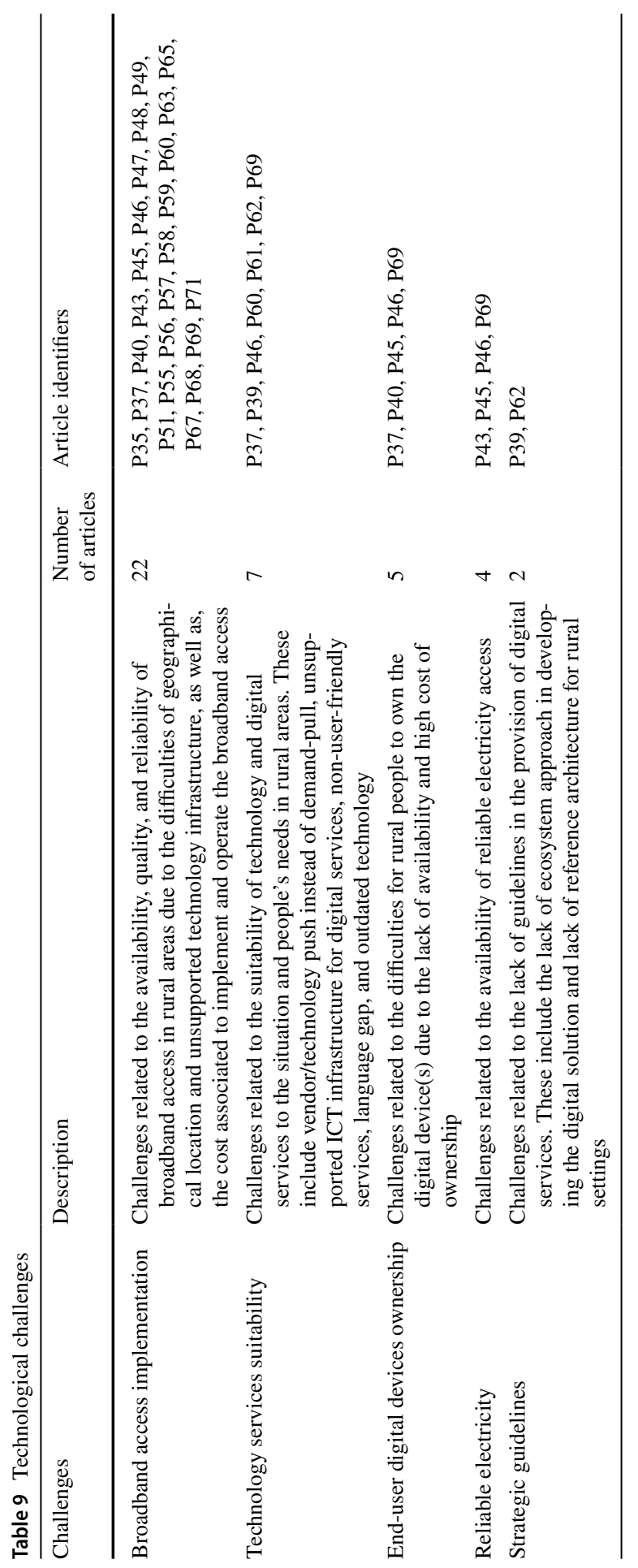




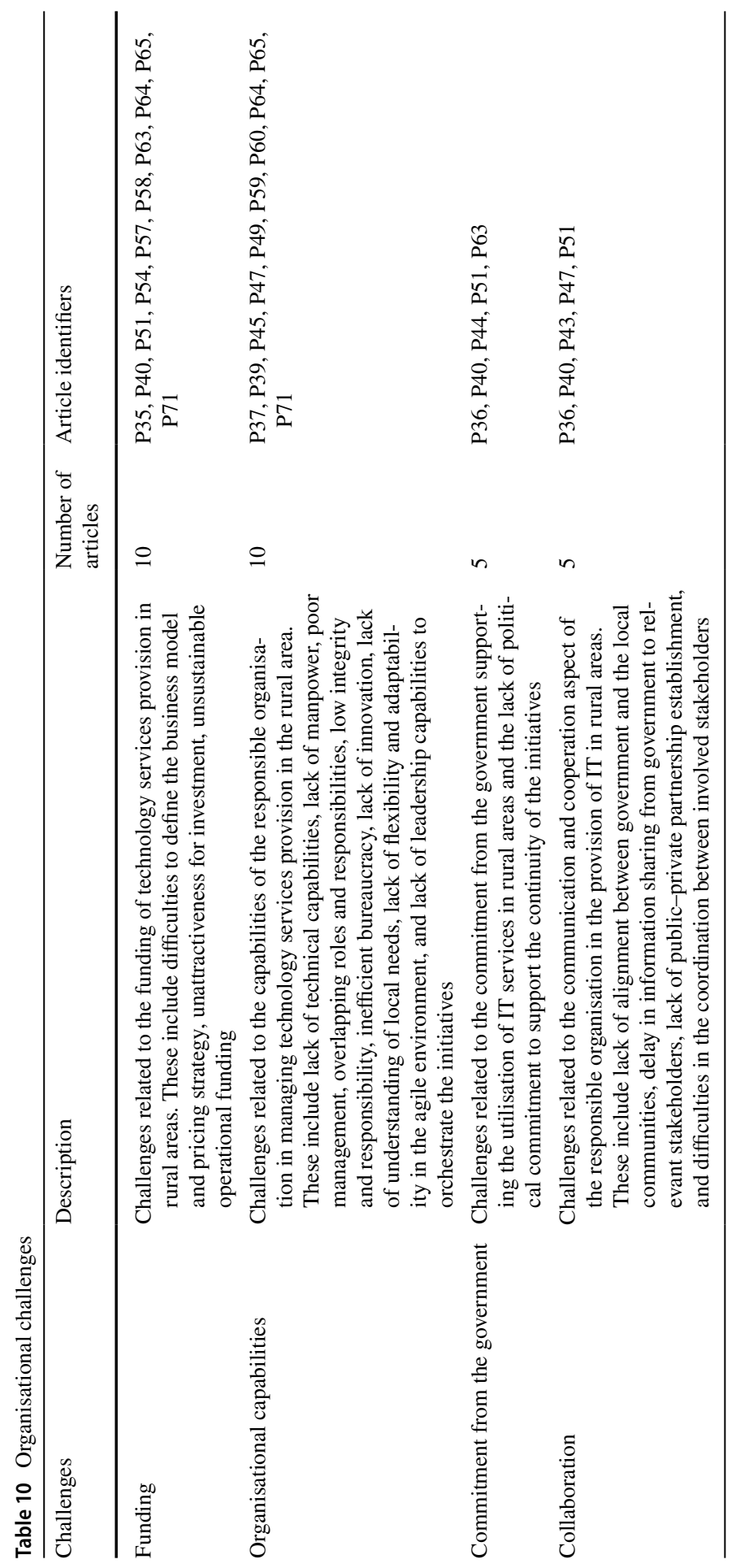




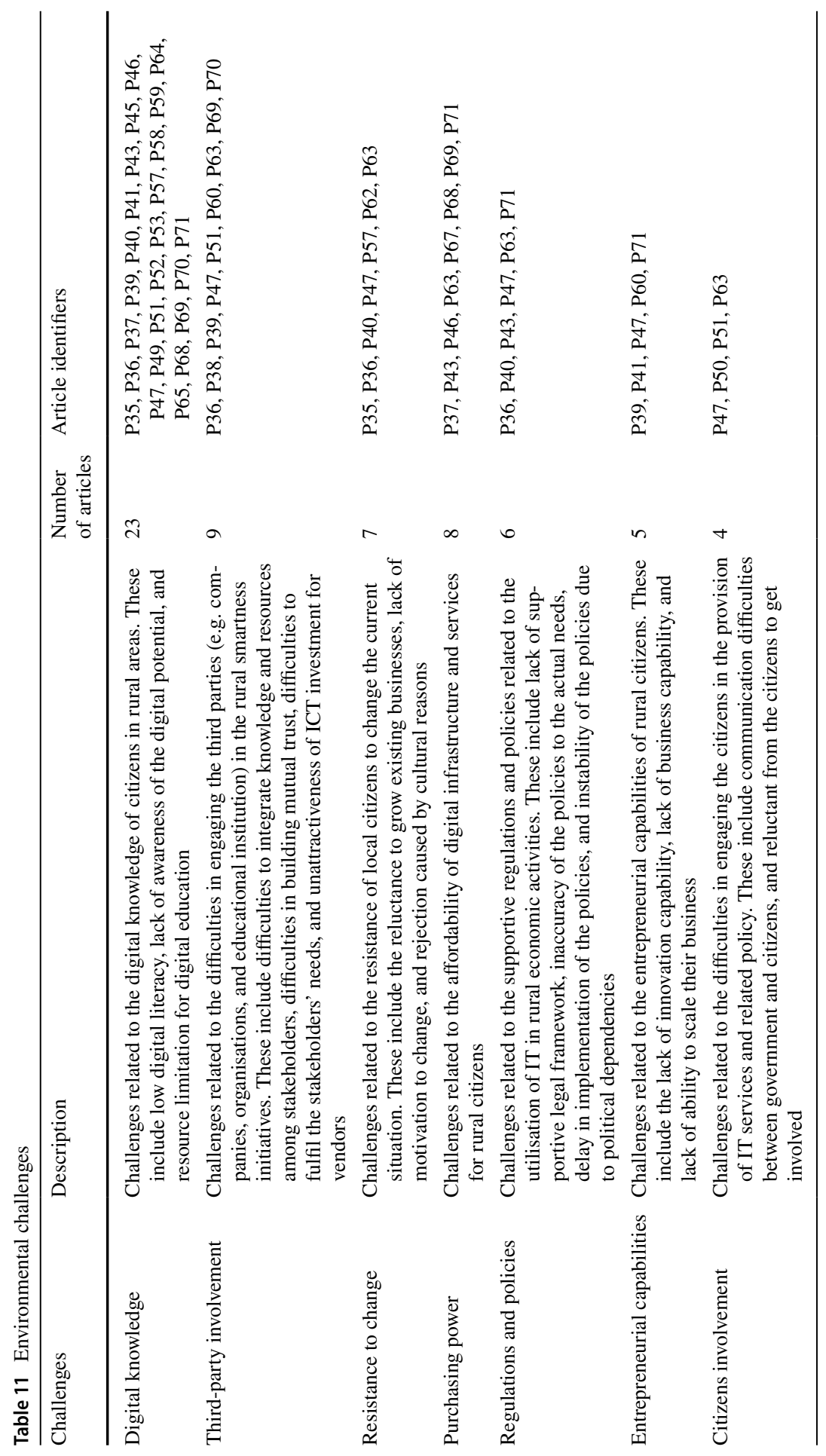




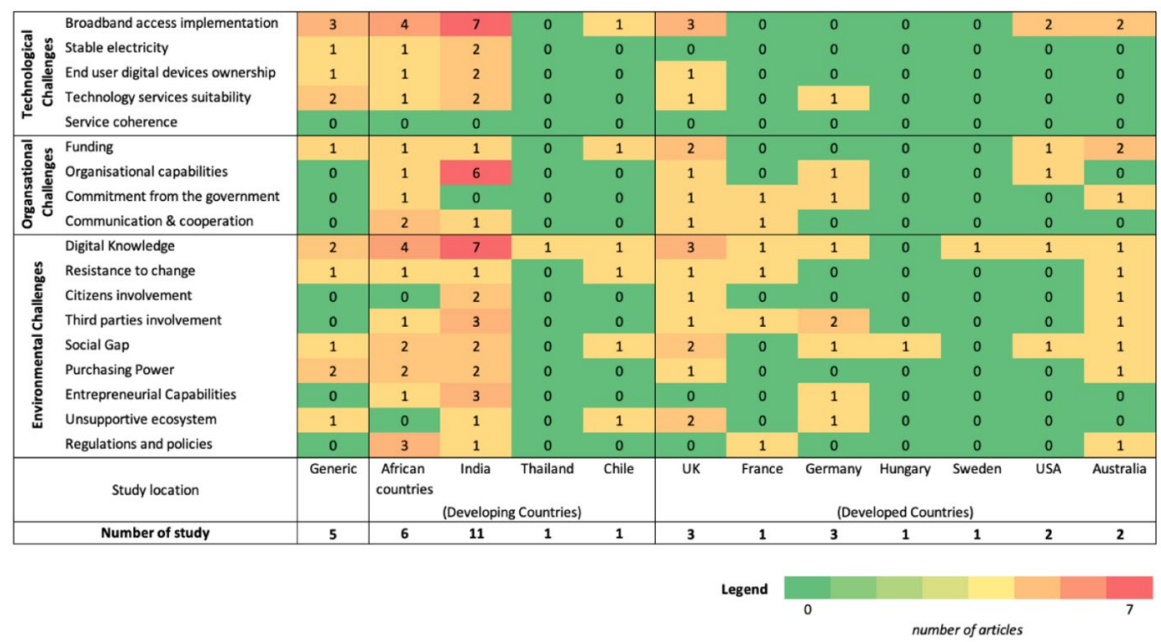

Fig. 9 Challenges mapping based on the location of study

the selected articles are carried out both in developing, and developed countries. However, the studies located in developed countries are more dispersed compared to those in developing countries. In developing countries, most of the studies concern African countries and India, where the citizens in rural areas represent a majority of the country's population (World Bank, 2018). Furthermore, the most cited challenges (the lack of broadband access, lack of organisational capability, and limited digital knowledge) are also identified by studies that carried out in India. Thus, these results suggest that the challenges identified in this section are most relevant for the developing countries (see Fig. 10).

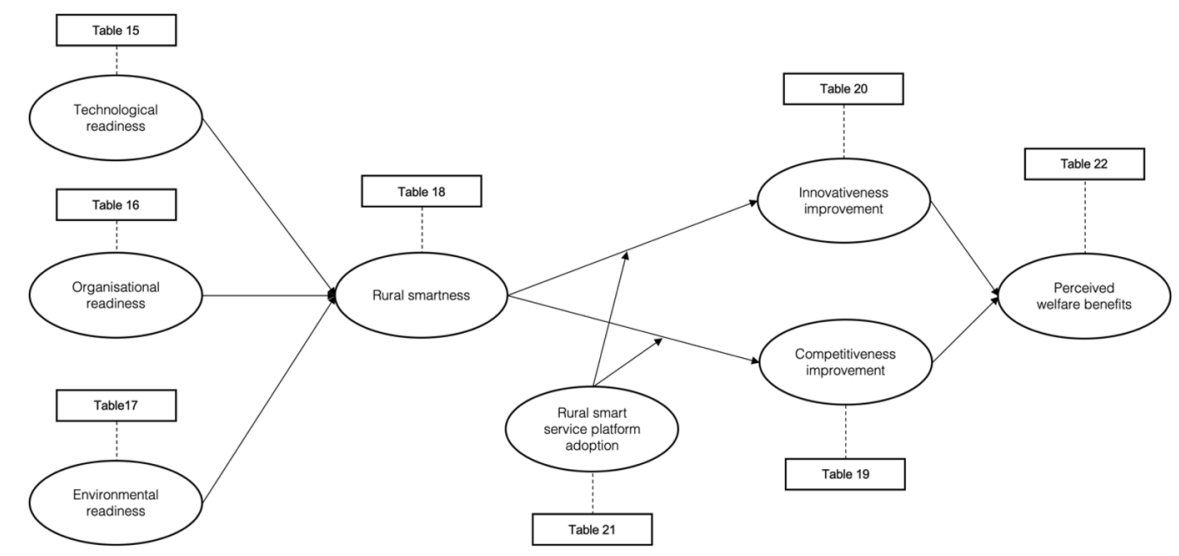

Fig. 10 Proposed theoretical model 


\section{Findings on RQ3}

The objective of RQ3 is to identify the state-of-the-art on service platforms, which represents the IT artefact of smartness. To achieve this objective, based on the results of the SLR, we identified several main functional characteristics, main types of technology used, and main categories of stakeholders involved in the service platforms.

Table 12 presents the main features of service platforms discussed in the selected literature. From the table, we can see that the most important features of service platforms are related to the ability to connect the stakeholders within the ecosystem. These features include the ability to integrate various services in a unified platform, accessibility of data by external parties, facilitation of services co-creation, facilitation of data management processes, of stakeholders' coordination, and of citizen's participation. However, other important features of service platforms remain underrepresented in the extant research, namely security and privacy, easiness to deploy, and easiness for end-users to use the platform.

Table 13 presents four categories of stakeholders mentioned in the literature. As it can be seen in the table, each of the stakeholder types appears in a significant number of articles (at least 20 articles). These results indicate that the design of service platforms should accommodate the collaboration between all these stakeholders' categories.

Table 14 presents six main technologies used by the service platforms. As it can be seen, two types of technologies that are most prevalent: (mobile) Internet access and data exchange infrastructure. Some authors also emphasize the importance of using open-source software components that enable service platforms to become vendor-independent.

\section{Discussion}

In this section, we discuss the formulation of the theoretical model that explains the causal mechanisms underlying the relationship between the adoption of rural smartness and improvement of the economic welfare of citizens in rural areas. The theoretical model has been derived from the articles we selected during the SLR. The articles on RQ1 are used to elaborate on the smartness characteristics that can contribute to the improvement of citizen's economic welfare, and to identify the specific economic impacts of smartness adoption. The articles on RQ2 are used to identify the readiness factors that need to be in place for the successful adoption of smartness in rural areas. Finally, the articles on RQ3 are used to define the characteristics of IT artefacts of smartness that can accelerate the positive economic impacts of smartness adoption in rural areas.

However, because our SLR is actually divided between three independent research domains/questions (determined by the three separate queries), the resulting literature sample is very much confined to these three domains and therefore not covering the links between them. Therefore, in order to link the three domains, and to be able rely on a sound theoretical foundation when 


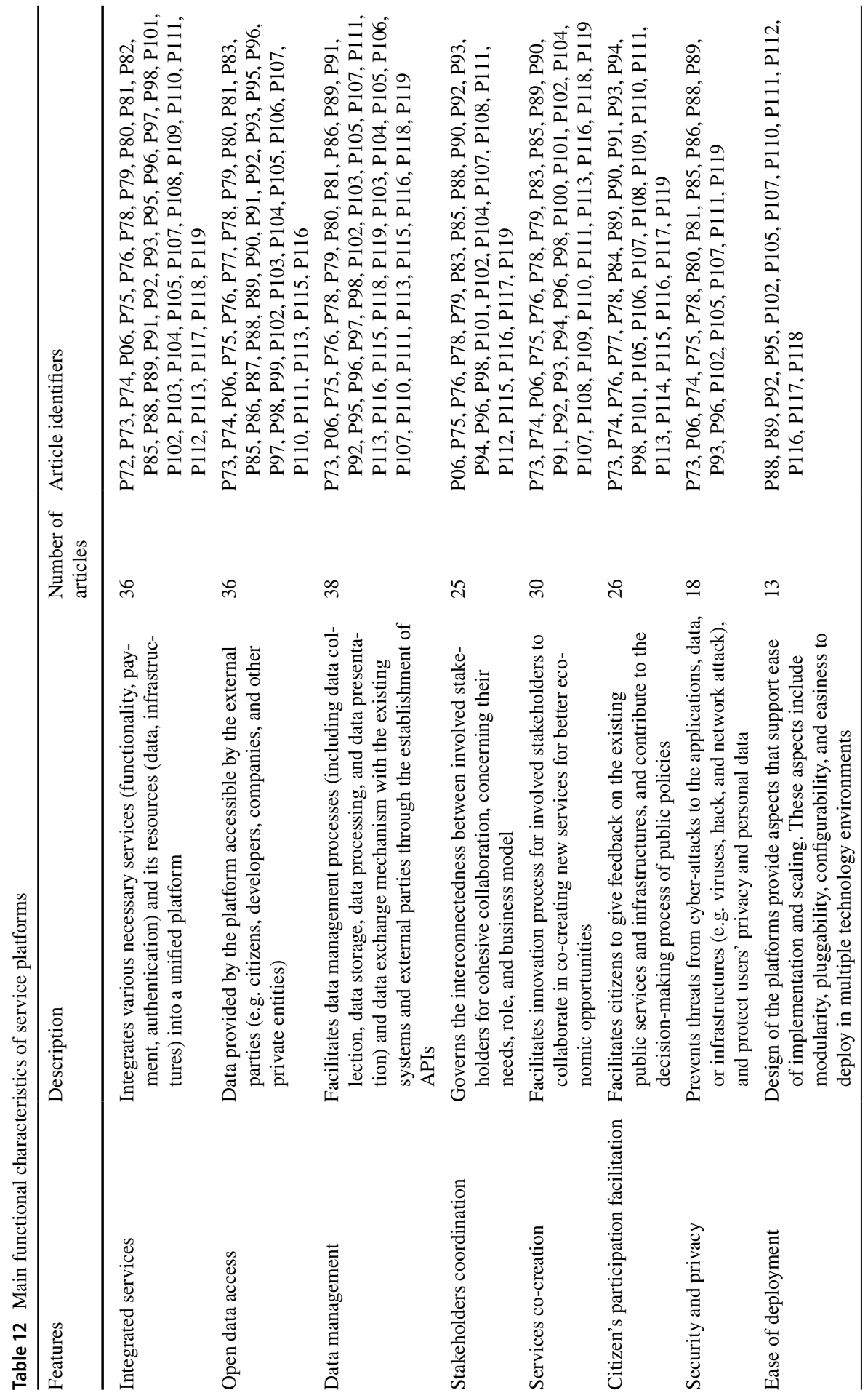




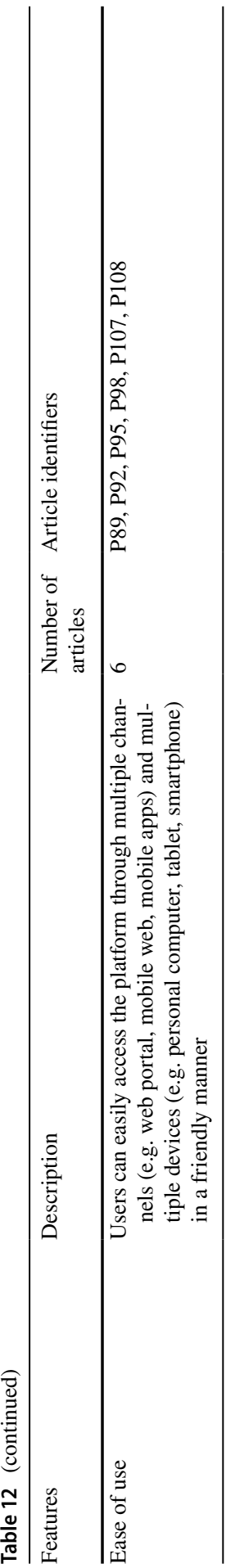

第 Springer 
Table 13 Involved stakeholders in a service platform

\begin{tabular}{|c|c|c|c|}
\hline Stakeholders & Description & $\begin{array}{l}\text { Number of } \\
\text { articles }\end{array}$ & Article identifiers \\
\hline Government & $\begin{array}{l}\text { Government entities, including } \\
\text { central government, municipal- } \\
\text { ity, and government agencies }\end{array}$ & 35 & $\begin{array}{l}\text { P73, P06, P75, P76, P79, P80, P81, P82, } \\
\text { P83, P88, P89, P90, P91, P92, P93, } \\
\text { P96, P97, P98, P101, P102, P103, } \\
\text { P104, P105, P106, P107, P108, P109, } \\
\text { P110, P111, P112, P113, P115, P116, } \\
\text { P117, P119 }\end{array}$ \\
\hline End users & $\begin{array}{l}\text { Entities using the services pro- } \\
\text { vided by the platform, including } \\
\text { citizens, communities, and } \\
\text { business entities (SMEs). }\end{array}$ & 35 & $\begin{array}{l}\text { P73, P06, P75, P76, P79, P80, P81, P82, } \\
\text { P83, P88, P89, P90, P91, P92, P93, } \\
\text { P96, P97, P98, P101, P102, P103, } \\
\text { P104, P105, P106, P107, P108, P109, } \\
\text { P111, P112, P113, P115, P116, P117, } \\
\text { P118, P119 }\end{array}$ \\
\hline $\begin{array}{l}\text { Business } \\
\text { service } \\
\text { providers }\end{array}$ & $\begin{array}{l}\text { Business entities providing goods } \\
\text { or services through the platform }\end{array}$ & 22 & $\begin{array}{l}\text { P73, P81, P83, P89, P90, P91, P93, P96, } \\
\text { P97, P98, P101, P102, P103, P104, } \\
\text { P108, P109, P110, P111, P113, P115, } \\
\text { P118, P119 }\end{array}$ \\
\hline $\begin{array}{r}\text { Technology } \\
\text { providers }\end{array}$ & $\begin{array}{l}\text { Entities that support the provision } \\
\text { of digital services provided } \\
\text { by the platforms, including } \\
\text { software developers, IT infra- } \\
\text { structure providers, and digital } \\
\text { services providers }\end{array}$ & 20 & $\begin{array}{l}\text { P06, P75, P76, P79, P88, P89, P90, } \\
\text { P91, P92, P93, P97, P98, P102, P107, } \\
\text { P108, P108, P111, P116, P117, P119 }\end{array}$ \\
\hline
\end{tabular}

structuring the theoretical model, we also use several other studies going beyond the SLR, namely, the TOE framework by Tornatzky and Fleischer (1990), the process-oriented model of IT business value by Mooney et al. (1996), the service innovation concept by Lusch and Nambisan (2015), and the service platform case study by Talbot (2016).

Figure 10 shows the proposed theoretical model. This model includes three independent variables (technological readiness, organizational readiness, and environmental readiness), three mediating variables (rural smartness, innovation improvement, and competitiveness improvement), one moderating variable (rural smart service platform adoption), and one dependent variable (perceived welfare benefits). In the remainder of this section, we will explain the rationale behind the proposed theoretical model.

To identify the variables that can predict the likelihood of the successful adoption of smartness in rural areas (rural smartness), we incorporate the TOE framework by Tornatzky and Fleischer (1990) into the theoretical model. The TOE framework has been widely used as the basis to study the adoption of various technology innovations. For example, electronic data interchange (Iacovou et al., 1995), e-business (Zhu et al., 2006), and enterprise resource planning (Awa et al., 2016). Although the TOE framework was initially developed in the context of organisations, as a general theory of technology innovation, this framework has been used to study technological innovation in urban areas as well, such as smart cities (Dewi et al., 2018; Bremser et al., 2019). 


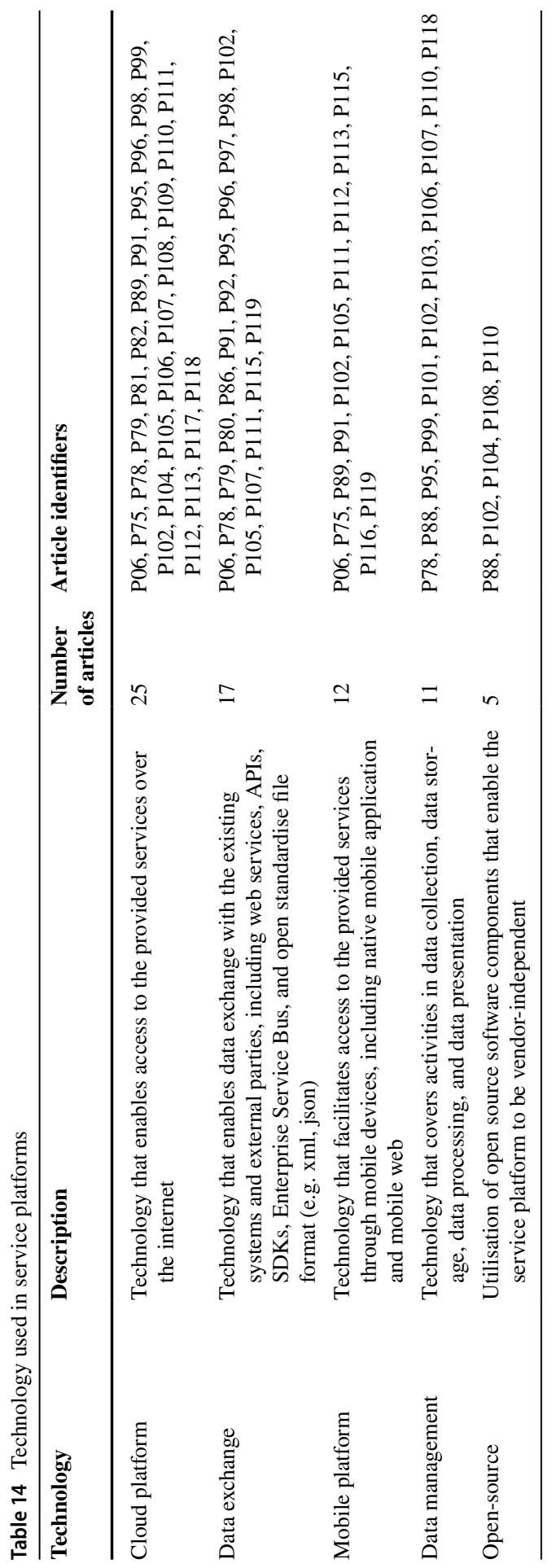


Given this wide applicability and relevance, we incorporate the TOE framework in the theoretical model to represent the independent variables that can influence the successful smartness adoption in rural areas: technological readiness, organisational readiness, and environmental readiness. Technological readiness covers the technology characteristics required as infrastructure for rural smartness. Organisational readiness covers the required characteristics and capabilities of the organisation responsible for the rural smartness initiatives. The environmental readiness covers the required characteristics of the involved stakeholders and of the regulatory environment that surrounds the initiatives for rural smartness.

To operationalise the readiness variables explained above, we refer to the challenges of rural smartness adoption that we identified in response to RQ2. We argue that by being ready to overcome these challenges, we can increase the likelihood to realise rural smartness. Indicators for technological readiness, organisational readiness, and environmental readiness are presented in Table 15, Table 16, and Table 17, respectively.

We used the term rural smartness to represent the successful adoption of smartness in rural areas. To further define the indicators of rural smartness, we refer to the smartness characteristics resulted from the SLR on RQ1. Based on these characteristics, we proposed four indicators of rural smartness in Table 18. According to these indicators, we can define rural smartness as the situation when the implementation of IT infrastructure and services can empower the citizens to improve their living quality and welfare through connectivity and participatory governance. This definition is aligned with the most widely cited definition of urban smartness by Andrea Caragliu et al. (2011). In the proposed theoretical model, we argue that rural smartness has a positive mediating effect on the economic welfare improvement for rural citizens.

To explain the positive impacts of rural smartness on the citizen's economic welfare, we refer to the process-oriented model of IT business value by Mooney et al. (1996). According to this model, benefits from IT adoption (smartness) are obtained through the impact that the smartness adoption has on the intermediate processes. Now, the question arising is what are the intermediate processes that can lead to the improvement of rural citizen's economic welfare. To answer this question, we use the service innovation concept by Lusch and Nambisan (2015).

They defined service innovation as the re-bundling of diverse resources that create novel resources (values) that are beneficial for entities in a given context. Such a conceptualisation leads to the understanding of the critical role IT has as a means to facilitate the exchange of resources between diverse stakeholders, and thus to accelerate the value creation process. We found that this concept is relevant for our model formulation since it helps us emphasize the role of IT in creating economic value. According to this concept, the use of IT that can support collaboration between diverse stakeholders within an ecosystem enables resource liquefaction and resource density.

Resource liquefaction refers to the digitisation process that decouples the information from its source. This digitisation leads to faster information processing and sharing and enables business entities in an ecosystem to have broader market access, more accurate business decision, and more productive use of available resources. Therefore, it enables the business entities to improve their competitiveness 


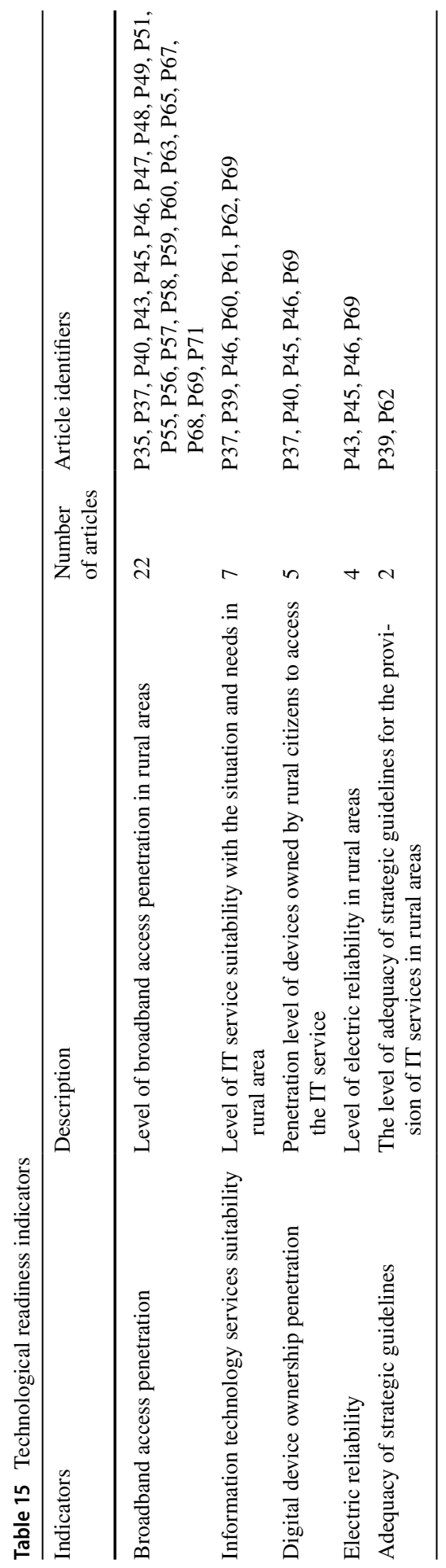




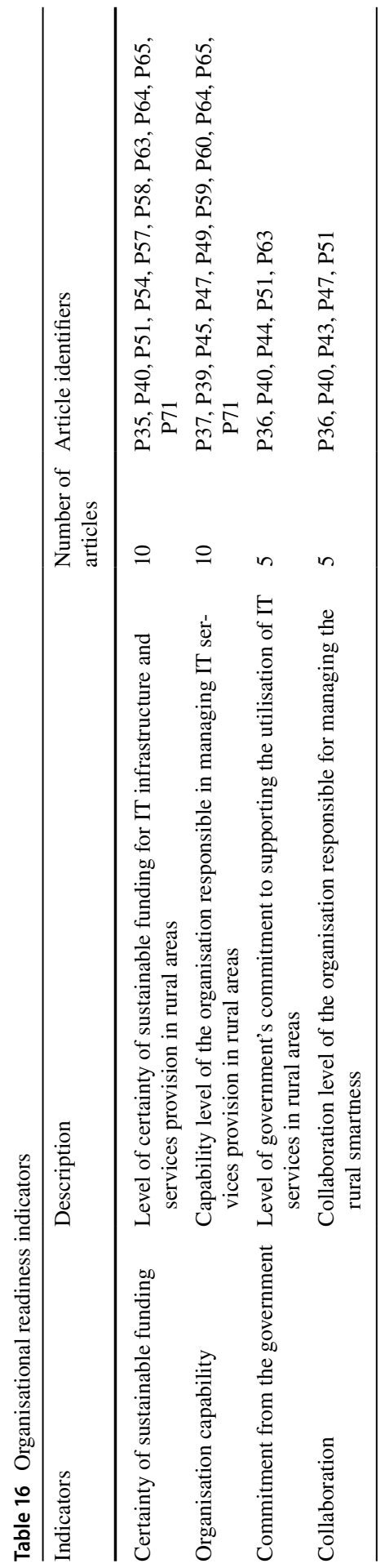




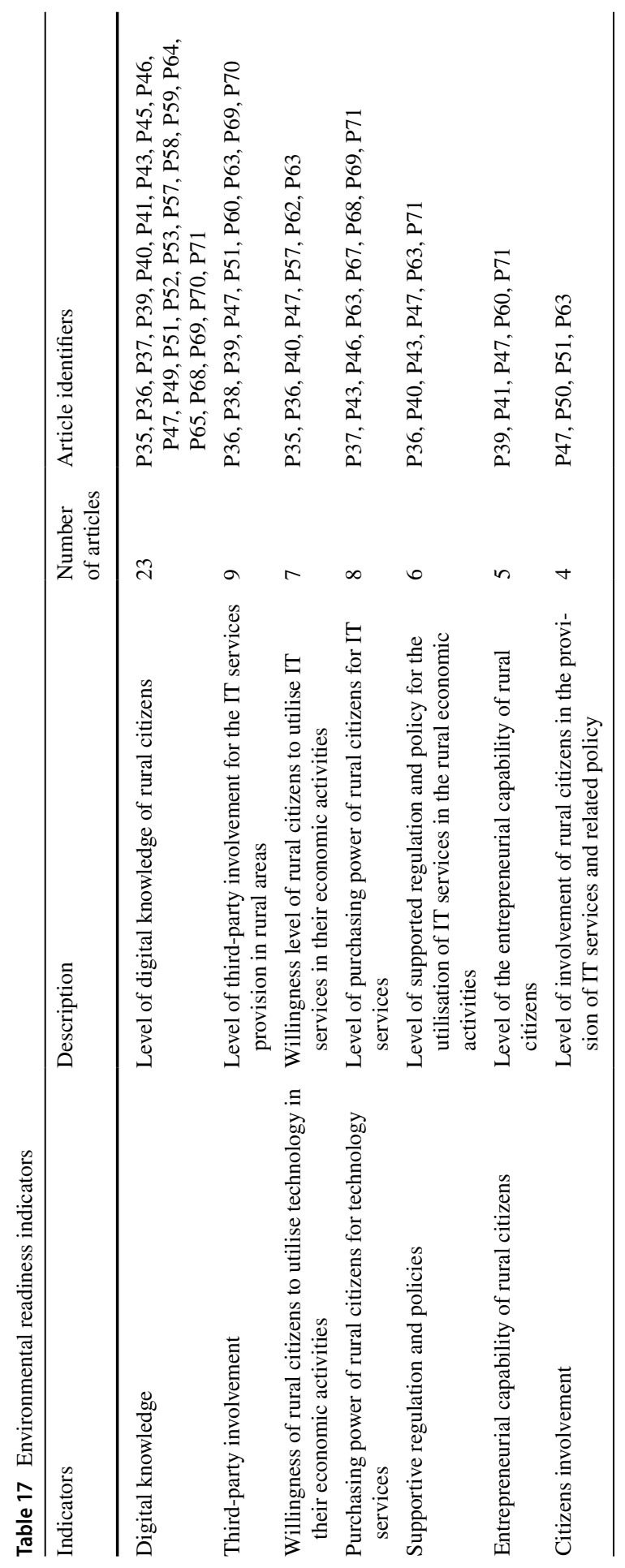




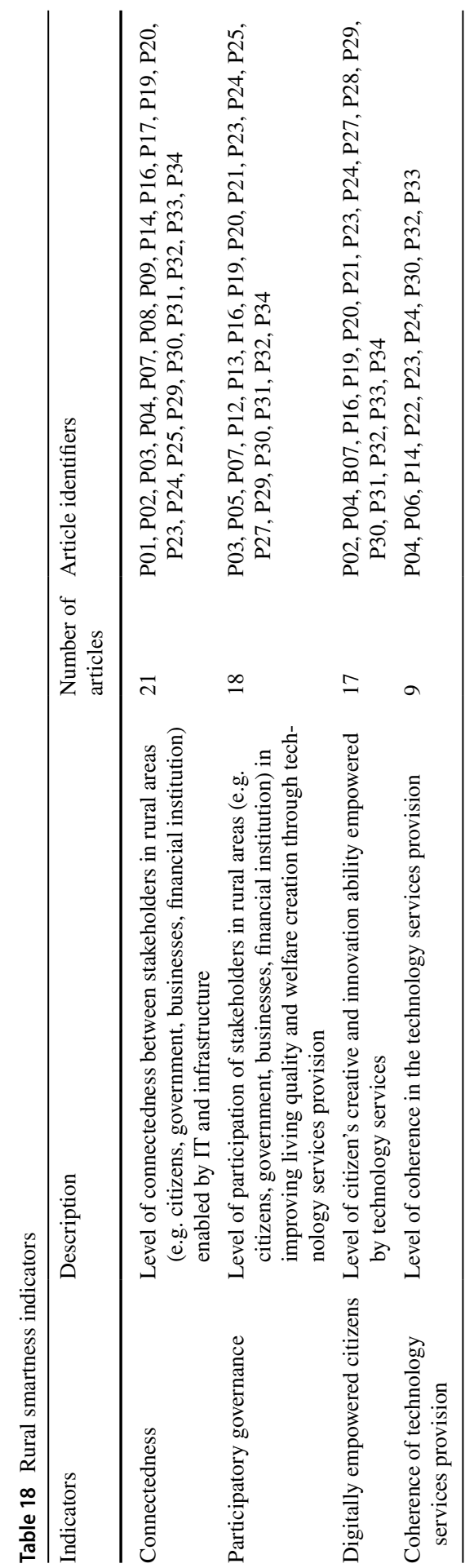


(Du Plessis and Marnewick, 2017; Borsekova et al., 2018; Okrepilov et al., 2019; Neirotti et al., 2014; Lusch and Nambisan, 2015). On the other hand, resource density refers to the ability of stakeholders in an ecosystem to exchange appropriate resources in the value creation process (Lusch and Nambisan, 2015). High resource density enables stakeholders to easily integrate various accessible resources that lead to a collaborative process resulting in the creation of new economic value, such as new products/services or new business entities (Lusch and Nambisan, 2015; Borsekova et al., 2018; F. Li et al., 2016; J. Yu et al., 2019).

Based on our understanding of the impact of smartness on resource liquefaction and resource density (explained above), we argue that the intermediate processes of smartness that lead to the improvement of rural citizen's economic welfare are competitiveness, and innovativeness improvement. Therefore, in the proposed theoretical model, we define competitiveness improvement and innovativeness improvement as the variables that mediate the impact of rural smartness on citizen's economic welfare. To operationalise these variables, based on the articles we selected for RQ1, indicators for competitiveness improvement and innovativeness improvement are presented in Table 19 and Table 20, respectively.

In terms of the IT artefact, our SLR results show that there is a growing interest concerning the utilisation of service platforms (see Fig. 7) as implementation and diffusion vehicle for smartness. According to the SLR results on RQ3, the main characteristics of a service platform can be summarised as follows: integrates various services in a unified platform, facilitates cohesive collaboration between stakeholders, facilitates the third parties to co-create services, and facilitates citizen's participation. These service platform characteristics are in line with the definition by Lusch and Nambisan (2015), in which a service platform is defined as a modular structure that consists of tangible and intangible components which facilitate the interaction between stakeholders and resources.

As mentioned earlier, according to Lusch and Nambisan (2015), the main benefits of service platforms is that they can leverage resource liquefaction and enhance resource density, which in turn can intensify competitiveness and innovativeness, respectively. To further understand the role of the service platform in the rural context, we refer to the study by Talbot (2016). The author conducted a case study on the utilisation of a service platform as a means to improve the economic situation in a rural area of Scotland. This study confirmed that the utilisation of service platforms enables entrepreneurs in rural areas to (1) recombine their existing productive assets and improve their competitiveness, and (2) collaborate with relevant stakeholders which leads to the innovative process for creating new economic values.

The aforementioned explanations motivate us to posit that the adoption of a service platform in rural areas can accelerate the impact rural smartness has on improving competitiveness and innovativeness. In our research, we named the service platform as the rural smart service platform. Therefore, in the proposed theoretical model, we define the adoption of a rural smart service platform as a variable that positively moderates the influence of rural smartness on business competitiveness and business innovation. To operationalise this variable, Table 21 proposes the indicators we identified during the SLR on RQ3. 


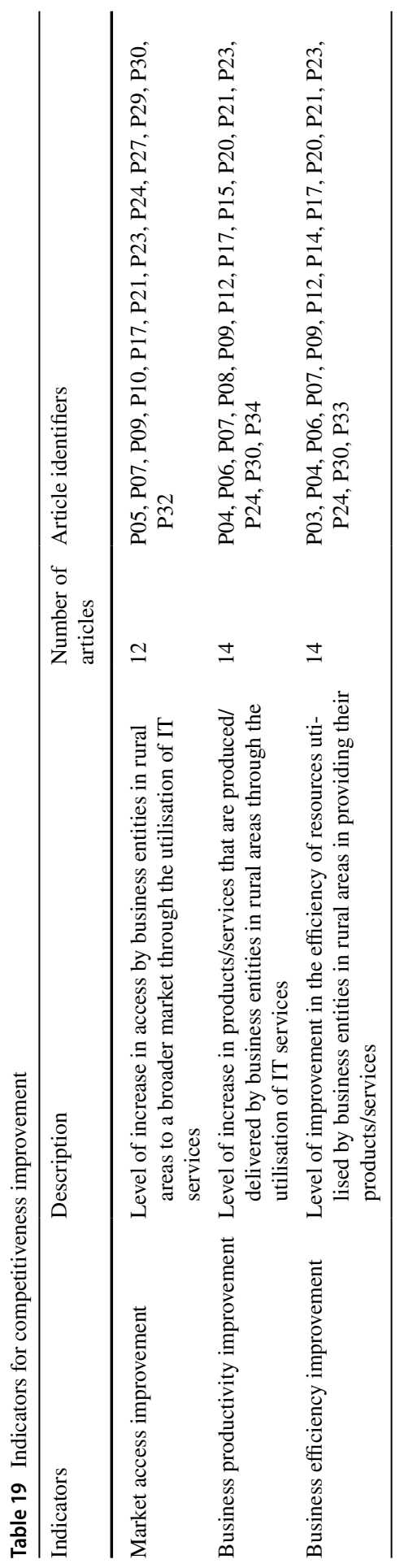




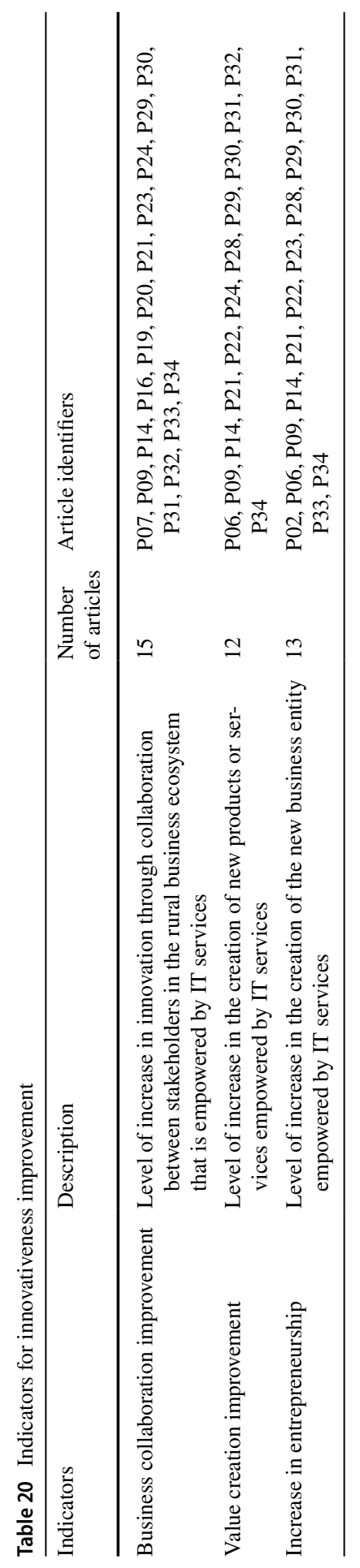




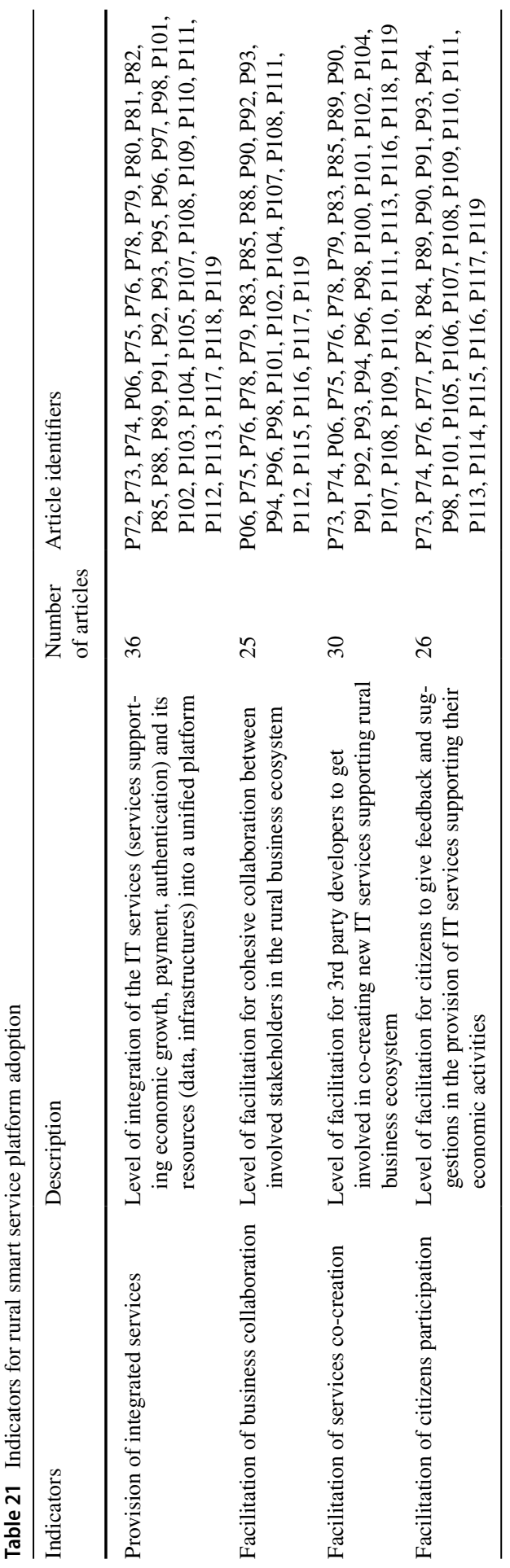




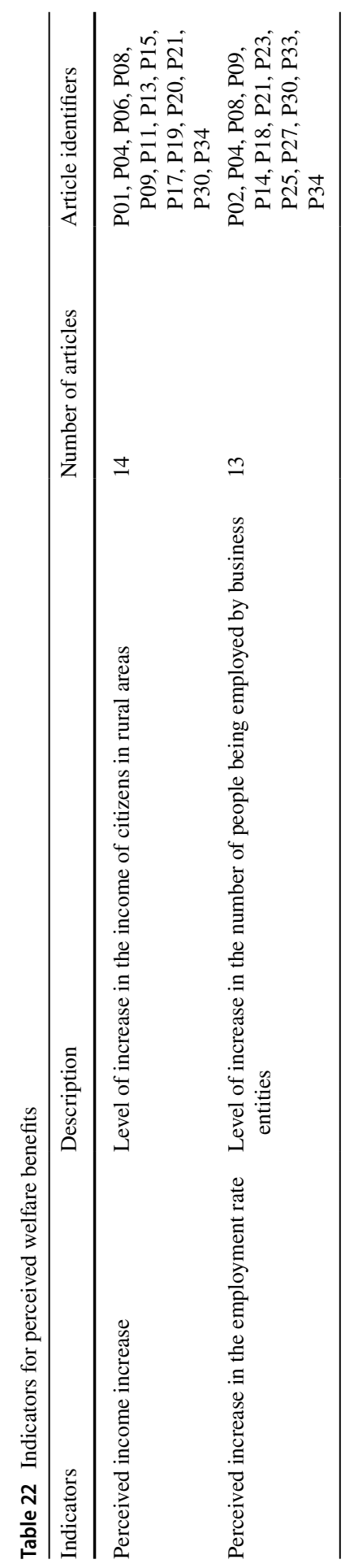


The improvement in competitiveness and innovativeness triggered by rural smartness and the rural smart service platform is stimulating economic growth that leads to the improvement of citizen's economic welfare (Zavratnik et al., 2018; Naldi et al., 2015; Talbot, 2016). However, it is not often possible to measure the benefits of IT innovation, such as smartness, in terms of a numerical value, since other intervening environmental variables may influence the value ( $\mathrm{Wu}$ and Wang, 2006). Therefore, several studies on IT adoption measured these benefits in terms of users' perceptions, e.g. perceived usefulness, perceived net benefits, and perceived individual impact (Wixom and Watson, 2001; Davis, 1989; McGill et al., 2003). Similarly, in the theoretical model, we use "perceived welfare benefits" as the dependent variable that represents the improvement of citizen's economic welfare. To operationalise this variable, in Table 22, we show the set of indicators resulting from analysis of the SLR on RQ1 (see Table 23).

The proposed theoretical model shown in Fig. 9 is an attempt to explain how rural smartness leads to the improvement of economic welfare for citizens in rural areas. However, an empirical test of this model, and a validity \& reliability check of the proposed candidate measures is beyond the scope of this paper, but is currently part of ongoing research in the West Java province of Indonesia. In its current form, the proposed theoretical model (and its operationalisation) led to the following recommendations:

1. To assure the realisation of rural smartness, attention should be given to preparing the technology, organisation, and environmental readiness as described in Table 15, Table 16, and Table 17.

2. There is a necessity to adopt a rural smart service platform as a means to improve the economic welfare of citizens in rural areas. We argue this adoption should have a significant moderating effect on the competitiveness and innovativeness of rural business entities.

3. To realise the moderating effect of the rural smart service platform adoption, design of such a platform should accommodate the necessary functional specifications represented by the indicators in Table 21 .

\section{Conclusion}

In this paper, we have conducted a systematic literature review resulting in a theoretical model that explains the causal mechanisms of how smartness adoption leads to the economic welfare improvement for citizens in rural areas. The main premise of the proposed theoretical model is that rural smartness has a mediating effect on the economic welfare of rural citizens through its positive influence on the competitiveness and innovativeness of rural business entities. Meanwhile, to realise smartness in rural areas, attention should be given to prepare the technology, organisation, and environmental readiness. Furthermore, we posit that there is a necessity to adopt a rural smart service platform. We argue that the adoption of such a platform should have a significant moderating effect on the competitiveness and innovativeness of rural business entities. 
This paper has limitations that generate directions of future research. First, the search process for the SLR was manually conducted in three academic databases in July 2019. This implies that we may have missed some relevant articles that were published after the period of search. Therefore, it is recommended for future research to include backward and forward snowballing search to have the maximum coverage of relevant articles.

Second, to achieve the objective, this paper mainly focused on analysing the content of the selected articles and only included a few descriptive statistical analysis based on bibliographic data. Therefore, to gain richer statistical insights, future research can complement the results of this paper by performing metric-based methodology, such as, bibliometrics or scientometrics, to the selected articles.

Third, relevant theories that we used as argument for the formulation of the theoretical model were not falling within the scope of the SLR. In future work a fine-tuning of this model can be achieved by identifying other possible alternative relevant theories which could result in a further consolidation of the structure of the model.

Fourth, this paper does not cover neither the empirical validation of the proposed theoretical model, nor the validity and reliability check of the proposed measurement instrument. Thus, our next step is to achieve this in an ongoing project in the West Java province.

\section{Appendix}

Table 23 Reference ID

\begin{tabular}{lll}
\hline ID & Reference & Relevance \\
\hline P01 & Giridhar Kamath et al. (2019) & RQ1 \\
P02 & Firmansyah et al. (2019) & RQ1 \\
P03 & Javidroozi et al. (2019) & RQ1 \\
P04 & Okrepilov et al. (2019) & RQ1 \\
P05 & Ramachandran et al. (2019) & RQ1 \\
P06 & J. Yu et al. (2019) & RQ1, RQ3 \\
P07 & Borsekova et al. (2018) & RQ1 \\
P08 & Cohen et al. (2018), & RQ1 \\
P09 & Indrawati et al. (2018) & RQ1 \\
P10 & Komarevtseva (2018) & RQ1 \\
P11 & Qu (2018) & RQ1 \\
P12 & Rothe et al. (2018), & RQ1 \\
P13 & Cowan et al. (2017) & RQ1 \\
P14 & Du Plessis and Marnewick (2017) & RQ1 \\
P15 & Han (2017) & RQ1 \\
P16 & Serrano-Santoyo and Rojas-Mendizabal (2017) & RQ1 \\
P17 & Shi et al. (2017) & RQ1 \\
P18 & Stankovic et al. (2017) & RQ1 \\
P19 & Tanda et al. (2017), & RQ1 \\
P20 & Yeh (2017) & RQ1 \\
P21 & Arroub et al. (2016) & RQ1 \\
\hline
\end{tabular}


Table 23 (continued)

\begin{tabular}{|c|c|c|}
\hline ID & Reference & Relevance \\
\hline$\overline{\mathrm{P} 22}$ & Ianuale et al. (2016) & RQ1 \\
\hline $\mathrm{P} 23$ & Joshi et al. (2016) & RQ1 \\
\hline $\mathrm{P} 24$ & F. Li et al. (2016) & RQ1 \\
\hline $\mathrm{P} 25$ & Makushkin et al. (2016) & RQ1 \\
\hline $\mathrm{P} 26$ & Rui (2016) & RQ1 \\
\hline $\mathrm{P} 27$ & Tahir and Malek (2016) & RQ1 \\
\hline $\mathrm{P} 28$ & Lavcak and Hudec (2015), & RQ1 \\
\hline $\mathrm{P} 29$ & Richter et al. (2015), & RQ1 \\
\hline P30 & Neirotti et al. (2014), & RQ1 \\
\hline $\mathrm{P} 31$ & Albino et al. (2013), & RQ1 \\
\hline P32 & Bakici et al. (2013) & RQ1 \\
\hline P33 & Mulligan and Olsson (2013), & RQ1 \\
\hline P34 & A. Caragliu and Del Bo (2012) & RQ1 \\
\hline P35 & Philip and Williams (2019) & RQ2 \\
\hline P36 & Soulard and Lardon (2019) & RQ2 \\
\hline P37 & Willis (2019) & RQ2 \\
\hline P38 & Doerr et al. (2018) & RQ2 \\
\hline P39 & Hosseini et al. (2018) & RQ2 \\
\hline $\mathrm{P} 40$ & Mtingwi et al. (2018) & RQ2 \\
\hline $\mathrm{P} 41$ & Jange and Chittaranjan (2018) & RQ2 \\
\hline P42 & Kaposzta et al. (2018) & RQ2 \\
\hline $\mathrm{P} 43$ & Manda and Backhouse (2018) & RQ2 \\
\hline P44 & Matern et al. (2018) & RQ2 \\
\hline $\mathrm{P} 45$ & Nedungadi et al. (2018) & RQ2 \\
\hline $\mathrm{P} 46$ & Gyeltshen and Osathanunkul (2018) & RQ2 \\
\hline P47 & Ray (2018) & RQ2 \\
\hline $\mathrm{P} 48$ & Aldoiu and Tapus (2018) & RQ2 \\
\hline P49 & Singh and Rahman (2018) & RQ2 \\
\hline P50 & Das and Misra (2017) & RQ2 \\
\hline P51 & Roberts et al. (2017) & RQ2 \\
\hline P52 & Wongkhamdi et al. (2017) & RQ2 \\
\hline P53 & Wihlborg and Engstrom (2017) & RQ2 \\
\hline P54 & S. Yu (2017)S. Yu (2017) & RQ2 \\
\hline P55 & Bertot (2016), & RQ2 \\
\hline P56 & Pham et al. (2016) & RQ2 \\
\hline P57 & Correa and Pavez (2016) & RQ2 \\
\hline P58 & Freeman et al. (2016) & RQ2 \\
\hline P59 & Katara (2016) & RQ2 \\
\hline $\mathrm{P} 60$ & Limaye et al. (2016) & RQ2 \\
\hline P61 & Nojozi et al. (2016) & RQ2 \\
\hline P62 & Jara et al. (2015) & RQ2 \\
\hline P63 & Freeman and Park (2015) & RQ2 \\
\hline P64 & Chatterjee and Kar (2015) & RQ2 \\
\hline
\end{tabular}


Table 23 (continued)

\begin{tabular}{|c|c|c|}
\hline ID & Reference & Relevance \\
\hline$\overline{\mathrm{P} 65}$ & Real et al. (2014) & RQ2 \\
\hline P66 & Das et al. (2013) & RQ2 \\
\hline P67 & Devkar et al. (2013) & RQ2 \\
\hline P68 & Figueiredo et al. (2012) & RQ2 \\
\hline P69 & Gore et al. (2012) & RQ2 \\
\hline P70 & Henriques and Kock (2012) & RQ2 \\
\hline P71 & Sumbwanyambe et al. (2011) & RQ2 \\
\hline P72 & Drozhzhin et al. (2019) & RQ3 \\
\hline P73 & Gil et al. (2019) & RQ3 \\
\hline P74 & Sanchez-Corcuera et al. (2019) & RQ3 \\
\hline P75 & Anindra et al. (2018) & RQ3 \\
\hline P76 & Barns (2018) & RQ3 \\
\hline P77 & Bolivar (2018) & RQ3 \\
\hline P78 & Chamoso et al. (2018) & RQ3 \\
\hline P79 & Gutierrez et al. (2018) & RQ3 \\
\hline P80 & Ishii and Yamanaka (2018) & RQ3 \\
\hline P81 & Koshizuka et al. (2018) & RQ3 \\
\hline P82 & Lv et al. (2018) & RQ3 \\
\hline P83 & Mahesa (2018) & RQ3 \\
\hline P84 & Muñoz and Rodríguez Bolívar (2018) & RQ3 \\
\hline P85 & Stone et al. (2018) & RQ3 \\
\hline P86 & Vieira and Alvaro (2018) & RQ3 \\
\hline P87 & Wang et al. (2018) & RQ3 \\
\hline P88 & Schieferdecker et al. (2017) & RQ3 \\
\hline P89 & Khan et al. (2017) & RQ3 \\
\hline P90 & Leminen et al. (2017) & RQ3 \\
\hline P91 & F. P. Li and $\mathrm{Li}(2017)$ & RQ3 \\
\hline P92 & Abu-Matar and Davies (2017) & RQ3 \\
\hline P93 & Pereira et al. (2017) & RQ3 \\
\hline P94 & Soomro et al. (2017) & RQ3 \\
\hline P95 & Usurelu and Pop (2017) & RQ3 \\
\hline P96 & Yamakami (2017) & RQ3 \\
\hline P97 & Abu-Matar (2016) & RQ3 \\
\hline P98 & Anttiroiko (2016) & RQ3 \\
\hline P99 & Bakerally et al. (2016) & RQ3 \\
\hline P100 & Coelho and Lopes (2016) & RQ3 \\
\hline P101 & Ojasalo and Kauppinen (2016) & RQ3 \\
\hline P102 & Recupero et al. (2016) & RQ3 \\
\hline P103 & Liu et al. (2016) & RQ3 \\
\hline P104 & Soto et al. (2016) & RQ3 \\
\hline P105 & Sakamura et al. (2015) & RQ3 \\
\hline P106 & Lopez et al. (2015) & RQ3 \\
\hline P107 & Yonezawa et al. (2015) & RQ3 \\
\hline
\end{tabular}


Table 23 (continued)

\begin{tabular}{lll}
\hline ID & Reference & Relevance \\
\hline P108 & Anttiroiko et al. (2014) & RQ3 \\
P109 & Clohessy et al. (2014) & RQ3 \\
P110 & Delaney and Pettit (2014) & RQ3 \\
P111 & F. Li and Wang (2014) & RQ3 \\
P112 & Piro et al. (2014) & RQ3 \\
P113 & Balena et al. (2013) & RQ3 \\
P114 & Benouaret et al. (2013) & RQ3 \\
P115 & Walravens (2013) & RQ3 \\
P116 & Walravens and Ballon (2013) & RQ3 \\
P117 & Kuk and Janssen (2011) & RQ3 \\
P118 & Maheshwari et al. (2011) & RQ3 \\
P119 & Walravens (2011) & RQ3 \\
\hline & &
\end{tabular}

Funding This research was carried out with the financial support of the Indonesia Endowment Fund for Education (LPDP) with grant number S-297/LPDP.3/2019, and supported by the Office of Communication and Information of West Java Province (Diskominfo Jabar), Indonesia.

Open Access This article is licensed under a Creative Commons Attribution 4.0 International License, which permits use, sharing, adaptation, distribution and reproduction in any medium or format, as long as you give appropriate credit to the original author(s) and the source, provide a link to the Creative Commons licence, and indicate if changes were made. The images or other third party material in this article are included in the article's Creative Commons licence, unless indicated otherwise in a credit line to the material. If material is not included in the article's Creative Commons licence and your intended use is not permitted by statutory regulation or exceeds the permitted use, you will need to obtain permission directly from the copyright holder. To view a copy of this licence, visit http://creativecommons.org/licenses/ by $/ 4.0 \%$.

\section{References}

Abu-Matar, M. Towards a software defined reference architecture for smart city ecosystems. In 2016 IEEE International Smart Cities Conference (ISC2), 12-15 Sept. 2016 (pp. 1-6). https://doi. org/10.1109/ISC2.2016.7580807.

Abu-Matar, M., \& Davies, J. Data driven reference architecture for smart city ecosystems. In 2017 IEEE SmartWorld, Ubiquitous Intelligence \& Computing, Advanced \& Trusted Computed, Scalable Computing \& Communications, Cloud \& Big Data Computing, Internet of People and Smart City Innovation, 4-8 Aug. 2017 (pp. 1-7). https://doi.org/10.1109/UIC-ATC.2017.8397556.

Albino, V., Berardi, U., \& Dangelico, R. M. (2013). Smart cities: definitions, dimensions, and performance (Ifkad 2013: 8th International Forum on Knowledge Asset Dynamics: Smart Growth: Organizations, Cities and Communities).

Albino, V., Berardi, U., \& Dangelico, R. M. (2015). Smart cities: Definitions, dimensions, performance, and initiatives. Journal of Urban Technology, 22(1), 3-21. https://doi.org/10.1080/10630732. 2014.942092.

Aldoiu, S., \& Tapus, N. Innovative infrastructure for Smart City/Smart Environment applications. In 2018 5th International Conference on Control, Decision and Information Technologies (CoDIT), 10-13 April 2018 (pp. 767-772). https://doi.org/10.1109/CoDIT.2018.8394822.

Angelidou, M. (2017). The role of smart city characteristics in the plans of fifteen cities. Journal of Urban Technology, 24(4), 3-28. https://doi.org/10.1080/10630732.2017.1348880. 
Anindra, F., Warnars, H. L. H. S., \& Min, D. M. Smart city implementation modelling in indonesia with integration platform approach. In Proceedings of 2018 International Conference on Information Management and Technology, ICIMTech 2018 (pp. 43-48). https://doi.org/10.1109/ICIMTech. 2018.8528141.

Anttiroiko, A. V. (2016). City-as-a-platform: The rise of participatory innovation platforms in finnish cities. [Article]. Sustainability, 8(9), https://doi.org/10.3390/su8090922.

Anttiroiko, A. V., Valkama, P., \& Bailey, S. J. (2014). Smart cities in the new service economy: Building platforms for smart services. [Article]. AI and Society,29(3), 323-334. https://doi.org/10.1007/ s00146-013-0464-0.

Arroub, A., Zahi, B., Sabir, E., \& Sadik, M. A . (2016). literature review on Smart Cities: Paradigms, opportunities and open problems. In Proceedings - 2016 International Conference on Wireless Networks and Mobile Communications, WINCOM 2016: Green Communications and Networking, 180-186. https://doi.org/10.1109/WINCOM.2016.7777211.

Awa, H. O., Ukoha, O., \& Emecheta, B. C. (2016). Using TOE theoretical framework to study the adoption of ERP solution. Cogent Business \& Management, 3(1), 1196571.

Bakerally, N., Boissier, O., \& Zimmermann, A. (2016). Smart City Artifacts Web Portal. In H. Sack, G. Rizzo, N. Steinmetz, D. Mladenic, S. Auer, \& C. Lange (Eds.), Semantic Web, Eswc 2016 (Vol. 9989, pp. 172-177, Lecture Notes in Computer Science).

Bakici, T., Almirall, E., \& Wareham, J. (2013). A smart city initiative: The case of Barcelona. [Article]. Journal of the Knowledge Economy, 4(2), 135-148. https://doi.org/10.1007/s13132-012-0084-9.

Balena, P., Bonifazi, A., \& Mangialardi, G. (2013). Smart communities meet urban management: Harnessing the potential of open data and public/private partnerships through innovative E-governance applications. In B. Murgante, S. Misra, M. Carlini, C. M. Torre, H. Q. Nguyen, D. Taniar, et al. (Eds.), Computational Science and Its Applications - Iccsa 2013, Pt Iv (Vol. 7974, pp. 528-540, Lecture Notes in Computer Science).

Barns, S. (2018). Smart cities and urban data platforms: Designing interfaces for smart governance. [Article]. City, Culture and Society, 12, 5-12. https://doi.org/10.1016/j.ccs.2017.09.006.

Benouaret, K., Valliyur-Ramalingam, R., \& Charoy, F. (2013). CrowdSC: Building smart cities with large-scale citizen participation. Ieee Internet Computing,17(6), 57-63. https://doi.org/10.1109/ mic.2013.88.

Bertot, J. C. (2016). Building digitally inclusive communities: The roles of public libraries in digital inclusion and development. In ACM International Conference Proceeding Series, 01,95-102. https:// doi.org/10.1145/2910019.2910082.

Bolivar, M. P. R. (2018). Creative citizenship: The new wave for collaborative environments in smart cities. Academia-Revista Latinoamericana De Administracion, 31(1), 277-302. https://doi. org/10.1108/arla-04-2017-0133.

Borsekova, K., Korony, S., Vanova, A., \& Vitalisova, K. (2018). Functionality between the size and indicators of smart cities: A research challenge with policy implications. Cities, 78, 17-26. https:// doi.org/10.1016/j.cities.2018.03.010.

Bremser, C., Piller, G., \& Rothlauf, F. How smart cities explore new technologies. In International Conference on Business Informatics Research, 2019 (pp. 1-15): Springer

Caragliu, A., \& Del Bo, C. (2012). Smartness and European urban performance: Assessing the local impacts of smart urban attributes. [Article]. Innovation: The European Journal of Social Science Research, 25(2), 97-113, https://doi.org/10.1080/13511610.2012.660323.

Caragliu, A., Del Bo, C., \& Nijkamp, P. (2011). Smart cities in Europe. Journal of Urban Technology, 18(2), 65-82. https://doi.org/10.1080/10630732.2011.601117.

Castañeda, A., Doan, D., Newhouse, D., Nguyen, M. C., Uematsu, H., \& Azevedo, J. P. (2018). A new profile of the global poor. World Development, 101, 250-267. https://doi.org/10.1016/j. worlddev.2017.08.002.

Chamoso, P., Gonzalez-Briones, A., Rodriguez, S., \& Corchado, J. M. (2018). Tendencies of technologies and platforms in smart cities: A state-of-the-art review. Wireless Communications \& Mobile Computing. https://doi.org/10.1155/2018/3086854.

Chatterjee, S., \& Kar, A. K. (2015) Smart Cities in developing economies: A literature review and policy insights. In 2015 International Conference on Advances in Computing, Communications and Informatics (ICACCI), 2335-2340. https://doi.org/10.1109/ICACCI.2015.7275967.

Clohessy, T., Acton, T., \& Morgan, L. (2014). Smart City as a Service (SCaaS) - A future roadmap for E-government smart city cloud computing initiatives. In 2014 Ieee/Acm 7th International 
Conference on Utility and Cloud Computing (836-+), International Conference on Utility and Cloud Computing.

Cocchia, A. (2014). Smart and digital city: A systematic literature review. In Smart City, 13-43, Progress in IS.

Coelho, S., \& Lopes, N. V. (2016). Online platform for case studies in smart cities. In 2016 International Multidisciplinary Conference on Computer and Energy Science, SpliTech 2016. https://doi. org/10.1109/SpliTech.2016.7555941.

Cohen, J., Bancilhon, J. M., \& Grace, T. (2018). Digitally connected living and quality of life: An analysis of the Gauteng City-Region, South Africa. Electronic Journal of Information Systems in Developing Countries, 84(1), https://doi.org/10.1002/isd2.12010.

Correa, T., \& Pavez, I. (2016). Digital inclusion in rural areas: A qualitative exploration of challenges faced by people from isolated communities. [Article]. Journal of Computer-Mediated Communication, 21(3), 247-263. https://doi.org/10.1111/jcc4.12154.

Cowan, D., Alencar, P., Young, K., Smale, B., Erb, R., \& McGarry, F. (2017). A model for the socially smart city practical uses of city-level socio-economic indicators. In J. Y. Nie, Z. Obradovic, T. Suzumura, R. Ghosh, R. Nambiar, C. Wang, et al. (Eds.), 2017 Ieee International Conference on Big Data, 4058-4067.

Das, R. K., \& Misra, H. (2017). Smart city and E-governance: Exploring the connect in the context of local development in India. In 2017 Fourth International Conference on eDemocracy \& eGovernment (ICEDEG), 232-233. https://doi.org/10.1109/ICEDEG.2017.7962540.

Das, R. K., Patra, M. R., \& Misra, H. (2013). E-governance and digital inclusion: Creating smart rural women in India. In ACM International Conference Proceeding Series, (pp. 144-149). https://doi. org/10.1145/2591888.2591911.

Davis, F. D. (1989). Perceived usefulness, perceived ease of use, and user acceptance of information technology. MIS Quarterly, 13(3), 319. https://doi.org/10.2307/249008.

De Magalhães, L., \& Santaeulàlia-Llopis, R. (2018). The consumption, income, and wealth of the poorest: An empirical analysis of economic inequality in rural and urban Sub-Saharan Africa for macroeconomists. Journal of Development Economics, 134, 350-371. https://doi.org/10.1016/j. jdeveco.2018.05.014.

Delaney, P., \& Pettit, C. (2014). Urban data hubs supporting smart cities. In CEUR Workshop Proceedings, (Vol. 1142, pp. 13-25)

Devkar, S., Lobo, S., \& Doke, P. (2013). smartHTTP: Improving rural mobile user experience. In 2013 5th IEEE International Conference on Broadband Network \& Multimedia Technology, 17-19 Nov. 2013, 160-164. https://doi.org/10.1109/ICBNMT.2013.6823935.

Dewi, M. A. A., Hidayanto, A. N., Betty, P., Kosandi, M., \& Budi, N. F. A. (2018). Smart city readiness model using technology- organization-environment (TOE) framework and its effect on adoption decision. In The Pacific Asia Conference on Information Systems

Doerr, J., Hess, A., \& Koch, M. (2018). RE and society - A perspective on RE in times of smart cities and smart rural areas. In Proceedings - 2018 IEEE 26th International Requirements Engineering Conference, RE 2018, 100-111. https://doi.org/10.1109/RE.2018.00020.

Drozhzhin, S. I., Shiyan, A. V., \& Mityagin, S. A. (2019). Smart city implementation and aspects: The case of St. Petersburg. In A. Chugunov, Y. Misnikov, E. Roshchin, \& D. Trutnev (Eds.), Electronic governance and open society: Challenges in Eurasia, Egose 2018 947, 14-25. Communications in Computer and Information Science.

Du Plessis, H., \& Marnewick, A. L. (2017). A roadmap for smart city services to address challenges faced by small businesses in South Africa. [Article]. South African Journal of Economic and Management Sciences, 20(1), https://doi.org/10.4102/sajems.v20i1.1631.

Figueiredo, M., Prado, P., \& Kramer, M. (2012). Overcoming poverty through digital inclusion. [Article]. IT Professional, 14(3), 6-10. https://doi.org/10.1109/MITP.2012.57.

Firmansyah, H. S., Supangkat, S. H., Arman, A. A., \& Giabbanelli, P. J. (2019). Identifying the components and interrelationships of smart cities in Indonesia: Supporting policymaking via fuzzy cognitive systems. IEEE Access, 7, 46136-46151. https://doi.org/10.1109/ACCESS.2019.2908622.

Freeman, J., \& Park, S. (2015). Rural realities: Digital communication challenges for rural Australian local governments. [Article]. Transforming Government: People, Process and Policy, 9(4), 465479. https://doi.org/10.1108/TG-03-2015-0012.

Freeman, J., Park, S., Middleton, C., \& Allen, M. (2016). The importance of broadband for socioeconomic development: A perspective from rural Australia. Australasian Journal of Information Systems, 20. 
Gil, O., Cortés-Cediel, M. E., \& Cantador, I. (2019). Citizen participation and the rise of digital media platforms in smart governance and smart cities. [Article]. International Journal of E-Planning Research, 8(1), 19-34. https://doi.org/10.4018/IJEPR.2019010102.

Giridhar Kamath, B., Barkur, G., \& Vibha. (2019). Impact of sustainable development on quality of life in smart cities: A causal approach. [Article]. International Journal of Mechanical Engineering and Technology, 10(2), 975-981.

Gore, K., Lobo, S., \& Doke, P. GappaGoshti ${ }^{\mathrm{TM}}$ : Digital inclusion for rural mass. In 2012 4th International Conference on Communication Systems and Networks, COMSNETS 2012. https://doi.org/10.1109/ COMSNETS.2012.6151383.

Grant, M. J., \& Booth, A. (2009). A typology of reviews: an analysis of 14 review types and associated methodologies. Health Information \& Libraries Journal, 26(2), 91-108.

Gutierrez, V., Amaxilatis, D., Mylonas, G., \& Munoz, L. (2018). Empowering citizens toward the co-creation of sustainable cities. IEEE Internet of Things Journal, 5(2), 668-676. https://doi. org/10.1109/jiot.2017.2743783.

Gyeltshen, P., \& Osathanunkul, K. (2018). Linking small-scale farmers to market using ICT. In 2018 International Conference on Digital Arts, Media and Technology (ICDAMT), (pp. 120-125). https:// doi.org/10.1109/ICDAMT.2018.8376507.

Han, Y. (2017). Smart city, smart growth. In L. Zhu, \& T. Zheng (Eds.), Proceedings of the 2017 2nd International Conference on Machinery, Electronics and Control Simulation (Vol. 138, pp. 580583, AER-Advances in Engineering Research).

Henriques , J. J., \& Kock, B. E. (2012). Empowering smallholders and local food markets with smartphones and social networks. In 2012 IEEE Global Humanitarian Technology Conference, 181-185. https://doi.org/10.1109/GHTC.2012.37.

Hood, W. W., \& Wilson, C. S. (2001). The literature of bibliometrics, scientometrics, and informetrics. Scientometrics, 52(2), 291. https://doi.org/10.1023/A:1017919924342.

Hosseini, S., Frank, L., Fridgen, G., \& Heger, S. (2018). Do not forget about smart towns: How to bring customized digital innovation to rural areas. [Article]. Business and Information Systems Engineering, 60(3), 243-257. https://doi.org/10.1007/s12599-018-0536-2.

Iacovou, C. L., Benbasat, I., \& Dexter, A. S. (1995). Electronic data interchange and small organizations: Adoption and impact of technology. MIS Quarterly, 19(4), 465-485. https://doi.org/10.2307/ 249629.

Ianuale, N., Schiavon, D., \& Capobianco, E. (2016). Smart cities, big data, and communities: Reasoning from the viewpoint of attractors. [Article]. IEEE Access, 4, 41-47. https://doi.org/10.1109/ACCESS. 2015.2500733.

Imai, K. S., Gaiha, R., \& Garbero, A. (2017). Poverty reduction during the rural-urban transformation: Rural development is still more important than urbanisation. Journal of Policy Modeling, 39(6), 963-982. https://doi.org/10.1016/j.jpolmod.2017.10.002.

Indrawati, Azkalhaq, N., \& Amani, H. (2018). Indicators to measure smart economy: An Indonesian perspective. In ACM International Conference Proceeding Series, 2018 173-179. https://doi. org/10.1145/3278252.3278278.

Ishii, K., \& Yamanaka, A. (2018). Building a common smart city platform utilizing FIWARE (case study of Takamatsu City). [Article]. NEC Technical Journal, 13(1), 28-31.

Jange, S., \& Chittaranjan, K. (2018). Rural Empowerment through Digital Knowledge Project in Hyderabad Karnataka, India : Regional Content, Access and Impact to Reach the Unreached. In IEEE 5th International Symposium on Emerging Trends and Technologies in Libraries and Information Services, ETTLIS 2018, 322-327. https://doi.org/10.1109/ETTLIS.2018.8485204.

Jara, A. J., Sun, Y., Song, H., Bie, R., Genooud, D., \& Bocchi, Y. (2015). Internet of things for cultural heritage of smart cities and smart regions. In 2015 IEEE 29th International Conference on Advanced Information Networking and Applications Workshops, 24-27 March 2015668-675. https:// doi.org/10.1109/WAINA.2015.169.

Javidroozi, V., Shah, H., \& Feldman, G. (2019). Smart city development: A business process-centric conceptualisation. In ICORES 2019 - Proceedings of the 8th International Conference on Operations Research and Enterprise Systems, 2019 (pp. 346-353)

Joshi, S., Saxena, S., Godbole, T., \& Shreya. (2016). Developing Smart Cities: An Integrated Framework. In Procedia Computer Science, 93, 902-909. https://doi.org/10.1016/j.procs.2016.07.258.

Kaposzta, J., Nagy, H., \& Solyomfi, H. A. (2018). Influence of security issues on sustainable and smart rural development in Hungary. In Engineering for Rural Development, 2018 (Vol. 17, pp. 477482). https://doi.org/10.22616/ERDev2018.17.N058. 
Katara, S. K. (2016). Envisioning smart villages through information and communication technologies-a framework for implementation in India. In International Conference on Digital Transformation and Global Society, 463-468: Springer.

Khan, Z., Dambruch, J., Peters-Anders, J., Sackl, A., Strasser, A., ... Frohlich, P. (2017). Developing knowledge-based citizen participation platform to support smart city decision making: The Smarticipate case study. Information, 8(2), https://doi.org/10.3390/info8020047.

Kitchenham, B., \& Charters, S. (2007). Guidelines for performing systematic literature reviews in software engineering (EBSE Technical Report, Vol. EBSE-2007-01): Department of Computer Science University of Durham Durham, UK.

Komarevtseva, O. O. (2019). A model for assessing the development of the economy of the "future cities" based on the regression data parameter constructive coste model. In CEUR Workshop Proceedings, 2018, 2258, 373-380.

Koshizuka, N., Haller, S., \& Sakamura, K. (2018). CPaaS.io: An EU-Japan collaboration on open smart city platforms. Computer, 51(12), 50-58. https://doi.org/10.1109/mc.2018.2880019.

Kuk, G., \& Janssen, M. (2011). The business models and information architectures of smart cities. Journal of Urban Technology, 18(2), 39-52. https://doi.org/10.1080/10630732.2011.601109.

Lagorio, A., Pinto, R., \& Golini, R. (2016). Research in urban logistics: A systematic literature review. International Journal of Physical Distribution \& Logistics Management, 46(10), 908-931. https:// doi.org/10.1108/ijpdlm-01-2016-0008.

Lavcak, M., \& Hudec, O. (2015). Factors of Smart Cities Influencing Startup Performance (Central European Conference in Finance and Economics).

Leminen, S., Rajahonka, M., \& Westerlund, M. (2017). Towards third-generation living lab networks in cities. Technology Innovation Management Review, 7(11), 21-35. https://doi.org/10.22215/ timreview/1118.

Li, F., Nucciarelli, A., Roden, S., \& Graham, G. (2016). How smart cities transform operations models: A new research agenda for operations management in the digital economy. [Article]. Production Planning and Control, 27(6), 514-528. https://doi.org/10.1080/09537287.2016.1147096.

Li, F., \& Wang, J. (2015). Citizen fusion service platform for smart cities: Architecture, technologies and practice. In 2014 IEEE International Conference on Global Software Engineeering Workshops, 18-18 Aug. 2014 (pp. 51-56). https://doi.org/10.1109/ICGSEW.2014.15.

Li, F. P., \& Li, B. (2017). Aggregating heterogeneous services in the smart city: The practice in China. In M. Qiu (Ed.), Smart Computing and Communication, Smartcom 2016 (Vol. 10135, pp. 449-458, Lecture Notes in Computer Science).

Limaye, R., Choudhary, R. K., Upadhyay, A., \& Yu, H. N. (2016). Smart village planning framework using extenics theory. In S. Cang, \& Y. Wang (Eds.), Proceedings of 2016 10th International Conference on Software, Knowledge, Information Management \& Applications (pp. 105-109, International Conference on Software Knowledge Information Management and Applications).

Linnenluecke, M. K., Marrone, M., \& Singh, A. K. (2020). Conducting systematic literature reviews and bibliometric analyses. Australian Journal of Management, 45(2), 175-194. https://doi. org/10.1177/0312896219877678.

Liu, S., Peng, L., Chi, T., \& Wang, X. (2016). Research on multi-source heterogeneous data collection for the Smart City public information platform. In 2016 IEEE International Geoscience and Remote Sensing Symposium (IGARSS), 10-15 July 2016 (pp. 623-626). https://doi.org/10.1109/IGARSS. 2016.7729156.

Lopez, V., Miñana, G., Sánchez, O., González, B., Valverde, G., \& Caro, R. (2015). Big+Open Data: Some applications for a Smartcity. In 2015 IEEE International Conference on Progress in Informatics and Computing (PIC), 18-20 Dec. 2015 (pp. 384-389). https://doi.org/10.1109/ PIC.2015.7489874.

Lusch, R. F., \& Nambisan, S. J. M. q. (2015). Service innovation: A service-dominant logic perspective. 39(1).

Lv, Z., Li, X., Wang, W., Zhang, B., Hu, J., \& Feng, S. (2018). Government affairs service platform for smart city. [Article]. Future Generation Computer Systems, 81, 443-451. https://doi.org/10.1016/j. future.2017.08.047.

Mahesa, R. Y. (2018). Gatot; Anggoro Yudo;. Platform ecosystems for Indonesia smart cities. In 2018 International Conference on Computer, Control, Informatics and its Applications, 2018: IEEE

Maheshwari, P., Kapoor, S., Kummamuru, K., \& Pingali, G. (2011). ICT enabled smart rural aggregation platform. In Proceedings - 2011 Annual SRII Global Conference, SRII 2011, 597-600. https://doi. org/10.1109/SRII.2011.66. 
Makushkin, S. A., Kirillov, A. V., Novikov, V. S., Shaizhanov, M. K., \& Seidina, M. Z. (2016). Role of inclusion "Smart city" concept as a factor in improving the socio-economic performance of the territory. [Article]. International Journal of Economics and Financial Issues, 6(1S), 152-156.

Manda, M. I., \& Backhouse, J. (2018). Inclusive digital transformation in South Africa: An institutional perspective. In ACM International Conference Proceeding Series, 464-470. https://doi. org/10.1145/3209415.3209486.

Martinez-Gil, J., Pichler, M., Beranič, T., Brezočnik, L., Turkanović, M., Lentini, G., et al. (2019). Framework for assessing the smartness maturity level of villages. In (pp. 501-512): Springer International Publishing.

Matern, A., Schroder, C., Stevens, J. M., \& Weidner, S. (2018). Provincial but smart-urban-rural relationships in Brandenburg/Germany. In A. Bisello, D. Vettorato, P. Laconte, \& S. Costa (Eds.), Smart and Sustainable Planning for Cities and Regions, Sspcr 2017, 551-562, Green Energy and Technology.

McGill, T., Hobbs, V., \& Klobas, J. J. I. R. M. J. (2003). User developed applications and information systems success: A test of DeLone and McLean's model., 16(1), 24-45.

Mishbah, M., Purwandari, B., \& Sensuse, D. I. (2018). Systematic review and meta-analysis of proposed smart village conceptual model: Objectives, strategies, dimensions, and foundations. In 2018 International Conference on Information Technology Systems and Innovation, ICITSI 2018 Proceedings, 127-133. https://doi.org/10.1109/ICITSI.2018.8696029.

Mooney, J. G., Gurbaxani, V., \& Kraemer, K. L. (1996). A process oriented framework for assessing the business value of information technology. The DATA BASE for Advances in Information System, 27(2), 68-81. https://doi.org/10.1145/243350.243363.

Mtingwi, J. E., Mawela, T., \& Leornad, A. (2018). M-Government Adoption framework for least developed countries: The case of Malawi. In 2018 International Conference on Intelligent and Innovative Computing Applications (ICONIC), 1-8. https://doi.org/10.1109/ICONIC.2018.8601213.

Mukti, I. Y. (2019). Defining, Designing, and Implementing Rural Smartness. Paper presented at the 2019 IEEE 23rd International Enterprise Distributed Object Computing Workshop (EDOCW), Paris, France,

Mulligan, C. E. A., \& Olsson, M. (2013). Architectural implications of smart city business models: An evolutionary perspective. [Article]. IEEE Communications Magazine, 51(6), 80-85. https://doi. org/10.1109/MCOM.2013.6525599.

Muñoz, L. A., \& Rodríguez Bolívar, M. P. (2018). Tools used by citizens for participation in European smart cities. ACM International Conference Proceeding Series. https://doi.org/10.1145/ 3209281.3225220 .

Naldi, L., Nilsson, P., Westlund, H., \& Wixe, S. (2015). What is smart rural development? Journal of Rural Studies, 40, 90-101. https://doi.org/10.1016/j.jrurstud.2015.06.006.

Nedungadi, P. P., Menon, R., Gutjahr, G., Erickson, L., \& Raman, R. (2018). Towards an inclusive digital literacy framework for digital India. [Article]. Education and Training, 60(6), 516-528. https://doi. org/10.1108/ET-03-2018-0061.

Neirotti, P., De Marco, A., Cagliano, A. C., Mangano, G., \& Scorrano, F. (2014). Current trends in smart city initiatives: Some stylised facts. [Article]. Cities, 38, 25-36. https://doi.org/10.1016/j.cities. 2013.12.010.

Nojozi, N., Scott, M. S., \& Nomnga, P. (2016). An m-agric application for broadcasting agricultural information for subsistence farmers in rural areas of the eastern cape. In 2016 IST-Africa Week Conference, 11-13 May 2016 (pp. 1-8). https://doi.org/10.1109/ISTAFRICA.2016.7530645.

Ojasalo, J., \& Kauppinen, H. (2016). Collaborative innovation with external actors: An empirical study on open innovation platforms in smart cities. Technology Innovation Management Review, 6(12), 49-60.

Okrepilov, V., Kuzmina, S., \& Kuznetsov, S. (2019). Tools of quality economics: Sustainable development of a 'smart city' under conditions of digital transformation of the economy. In IOP Conference Series: Materials Science and Engineering, (1 ed., Vol. 497). https://doi. org/10.1088/1757-899X/497/1/012134.

Østby, G. (2016). Rural-urban migration, inequality and urban social disorder: Evidence from African and Asian cities. Conflict Management and Peace Science, 33(5), 491-515. https://doi. org/10.1177/0738894215581315.

Paré, G., Trudel, M.-C., Jaana, M., \& Kitsiou, S. (2015). Synthesizing information systems knowledge: A typology of literature reviews. Information \& Management, 52(2), 183-199. https://doi. org/10.1016/j.im.2014.08.008. 
Pereira, G. V., Macadar, M. A., Luciano, E. M., \& Testa, M. G. (2017). Delivering public value through open government data initiatives in a Smart City context. [Article]. Information Systems Frontiers, 19(2), 213-229. https://doi.org/10.1007/s10796-016-9673-7.

Pham, C., Rahim, A., \& Cousin, P. (2016). Low-cost, Long-range open IoT for smarter rural African villages. In 2016 IEEE International Smart Cities Conference (ISC2), 1-6. https://doi.org/10.1109/ ISC2.2016.7580823.

Philip, L., \& Williams, F. (2019). Remote rural home based businesses and digital inequalities: Understanding needs and expectations in a digitally underserved community. [Article]. Journal of Rural Studies, 68, 306-318. https://doi.org/10.1016/j.jrurstud.2018.09.011.

Piro, G., Cianci, I., Grieco, L. A., Boggia, G., \& Camarda, P. (2014). Information centric services in Smart Cities. Journal of Systems and Software, 88, 169-188. https://doi.org/10.1016/j. jss.2013.10.029.

Qu, Y. (2016). Evaluation of smart city development potential in major cities of China based on the KPCA method. In International Conference on Management Science and Engineering - Annual Conference Proceedings, 2018, 855-862. https://doi.org/10.1109/ICMSE.2016.8365527.

Ramachandran, G. S., Radhakrishnan, R., \& Krishnamachari, B. (2018). Towards a Decentralized Data Marketplace for Smart Cities. In 2018 IEEE International Smart Cities Conference, ISC2 2018, 2019. https://doi.org/10.1109/ISC2.2018.8656952.

Ray, P. P. (2018). Digital India: Perspective, challenges and future direction. In 2018 International Conference on Power, Signals, Control and Computation (EPSCICON), 1-8. https://doi. org/10.1109/EPSCICON.2018.8379594.

Real, B., Bertot, J. C., \& Jaeger, P. T. (2014). Rural public libraries and digital inclusion: Issues and challenges. Information Technology and Libraries, 33(1), 6-24. https://doi.org/10.6017/ital. v33i1.5141.

Recupero, D. R., Castronovo, M., Consoli, S., Costanzo, T., Gangemi, A., ... Grasso, L., (2016). An innovative, open, interoperable citizen engagement cloud platform for smart government and users' interaction. Journal of the Knowledge Economy, 7(2), 388-412. https://doi.org/10.1007/s13132016-0361-0.

Richter, C., Kraus, S., \& Syrja, P. (2015). The Smart City as an opportunity for entrepreneurship. International Journal of Entrepreneurial Venturing, 7(3), 211-226. https://doi.org/10.1504/ ijev.2015.071481.

Roberts, E., Anderson, B. A., Skerratt, S., \& Farrington, J. (2017). A review of the rural-digital policy agenda from a community resilience perspective. [Article]. Journal of Rural Studies, 54, 372-385. https://doi.org/10.1016/j.jrurstud.2016.03.001.

Roland Berger (2017). Roland Berger Trend Compendium 2030, Megatrend 1. Roland Berger.

Rothe, R., Rutkowska, M., \& Sulich, A. (2018). Smart cities and challenges for European integration. Proceedings of the 4th International Conference on European Integration 2018 (Icei 2018), Pts $1-3,1240-1246$.

Rouhani, B. D., Mahrin, M. N., \& Nikpay, F., Ahmad, R. B., \& Nikfard, P. (2015). A systematic literature review on enterprise architecture implementation methodologies. Information and Software Technology, 62, 1-20. https://doi.org/10.1016/j.infsof.2015.01.012.

Rui, C. A. (2016). new smart city appraisal method based on conditional Shannon entropy and rough set theory. In 2016 9th International Symposium on Computational Intelligence and Design (ISCID), 10-11 Dec. 20162016 (Vol. 1, pp. 225-228). https://doi.org/10.1109/ISCID.2016.1058.

Sakamura, M., Yonezawa, T., Ito, T., Nakazawa, J., \& Tokuda, H. (2015). MinaQn: Web-based participatory sensing platform for citizen-centric urban development. In UbiComp and ISWC 2015 - Proceedings of the 2015 ACM International Joint Conference on Pervasive and Ubiquitous Computing and the Proceedings of the 2015 ACM International Symposium on Wearable Computers, 1607-1614. https://doi.org/10.1145/2800835.2801632.

Samnani, S. S., Vaska, M., Ahmed, S., \& Turin, T. C. (2017). Review typology: The basic types of reviews for synthesizing evidence for the purpose of knowledge translation. Journal of the College of Physicians and Surgeons Pakistan, 27(10), 635-641.

Sanchez-Corcuera, R., Nunez-Marcos, A., Sesma-Solance, J., Bilbao-Jayo, A., Mulero, R., ... Zulaika, U. (2019). Smart cities survey: Technologies, application domains and challenges for the cities of the future. International Journal of Distributed Sensor Networks, 15(6), https://doi.org/10.1177/ 1550147719853984.

Santhiyakumari, N., Shenbagapriya, M., \& Hemalatha, R. A (2016). novel approach in information and communication technology combined with traditional practices for smart villages. In 2016 IEEE 
Region 10 Humanitarian Technology Conference (R10-HTC ), 1-5 https://doi.org/10.1109/R10HTC.2016.7906843.

Schieferdecker, I., Tcholtchev, N., Lämmel, P., Scholz, R., \& Lapi, E. (2017). Towards an open data based ICT reference architecture for smart cities. In 2017 Conference for E-Democracy and Open Government (CeDEM), 184-193. https://doi.org/10.1109/CeDEM.2017.18.

Serrano-Santoyo, A., \& Rojas-Mendizabal, V. (2017). Exploring a complexity framework for digital inclusion interventions. In Procedia Computer Science, 121, 212-217. https://doi.org/10.1016/j. procs.2017.11.029.

Shaffril, H. A. M., Samsuddin, S. F., \& Abu Samah, A. (2020). The ABC of systematic literature review: The basic methodological guidance for beginners. Quality \& Quantity. https://doi.org/10.1007/ s11135-020-01059-6.

Shi, L., He, S. Y., \& Song, C. (2017). Research on transforming capability of economic system and its impact on urban competitiveness. In Proceedings of the International Conference on Electronic Business (ICEB), 228-233.

Sicular, T., Ximing, Y., Gustafsson, B., \& Shi, L. (2007). The urban-rural income gap and inequality in China. Review of Income and Wealth, 53(1), 93-126. https://doi.org/10.1111/ j.1475-4991.2007.00219.x.

Singh, C., \& Rahman, A. (2018). Urbanising the rural: Reflections on India's National Rurban Mission. [Article]. Asia and the Pacific Policy Studies, 5(2), 370-377. https://doi.org/10.1002/app5.234.

Soomro, K., Khan, Z., \& Ludlow, D. (2017). Participatory governance in smart cities: the urban API case study. International Journal of Services Technology and Management, 23(5-6), 419-444. https:// doi.org/10.1504/ijstm.2017.10009859.

Soto, J. A. C., Werner-Kytola, O., Jahn, M., Pullmann, J., Bonino, D., ... Pastrone, C. (2016). Towards a Federation of Smart City Services. In M. Alhaisoni, \& R. A. Ramadan (Eds.), Proceedings of the 2015 International Conference on Recent Advances in Computer Systems, 38, 163-168, ACSRAdvances in Comptuer Science Research.

Soulard, C. T., \& Lardon, S. (2019). Action-research helps researchers foster smart rural development: Two case studies on local food policy. [Article]. Systemic Practice and Action Research, 32(2), 155-166. https://doi.org/10.1007/s11213-018-9469-4.

Stankovic, J., Dzunic, M., Dzunic, Z., \& Marinkovic, S. (2017). A multi-criteria evaluation of the European cities' smart performance: Economic, social and environmental aspects. Proceedings of Rijeka Faculty of Economics, Journal of Economics and Business, 35(2), 519-550, https://doi. org/10.18045/zbefri.2017.2.519.

Stone, M., Knapper, J., Evans, G., \& Aravopoulou, E. (2018). Information management in the smart city. [Article]. Bottom Line, 31(3-4), 234-249. https://doi.org/10.1108/BL-07-2018-0033.

Sumbwanyambe, M., Nel, A., \& Clarke, W. (2011). Challenges and proposed solutions towards telecentre sustainability: A Southern Africa case study. In 2011 IST-Africa Conference Proceedings, 11-13 May 2011 (pp. 1-8)

Tahir, Z., \& Malek, J. A. (2016). Main criteria in the development of smart cities determined using analytical method. [Article]. Planning Malaysia, 14, 1-14. https://doi.org/10.21837/pmjournal. v14.i5.179.

Talbot, S. (2016). Creating a smart rural economy through smart specialisation: The microsphere model. Local Economy, 31(8), 892-919. https://doi.org/10.1177/0269094216678601.

Tanda, A., De Marco, A., \& Rosso, M. (2017). Evaluating the impact of smart city initiatives the torino living lab experience. In SMARTGREENS 2017 - Proceedings of the 6th International Conference on Smart Cities and Green ICT Systems, (pp. 281-286)

Tornatzky, L. G., \& Fleischer, M. (1990). The processes of technological innovation. MA: Lexington books.

United Nations. (2018). World Urbanization Prospects: The 2018 Revision [key facts]. (pp. 1).

United Nations. (2020). World Economic Situation and Prospects. New York: United Nations.

Usurelu, C. C., \& Pop, F. (2017). My city dashboard: Real-time data processing platform for smart cities. [Article]. Journal of Telecommunications and Information Technology, 2017(1), 89-100.

Vieira, D. I., \& Alvaro, A. (2018). A centralized platform of open government data as support to applications in the smart cities context. [Article]. International Journal of Web Information Systems, 14(1), 2-28. https://doi.org/10.1108/IJWIS-05-2017-0045.

Walravens, N. (2011). The city as a platform: A case-based exploration of mobile service platform types in the context of the city. In 2011 15th International Conference on Intelligence in Next Generation Networks, ICIN 2011, 283-288. https://doi.org/10.1109/ICIN.2011.6081090. 
Walravens, N. (2013). The city as a service platform: A typology of city platform roles in mobile service provision. In 19th Americas Conference on Information Systems, AMCIS 2013 - Hyperconnected World: Anything, Anywhere, Anytime, 5, 3271-3277.

Walravens, N., \& Ballon, P. (2013). Platform business models for smart cities: From control and value to governance and public value. [Article]. IEEE Communications Magazine, 51(6), 72-79. https://doi. org/10.1109/MCOM.2013.6525598.

Wang, X., Fang, Y., Liu, Y., \& Horn, B. A. (2018). survey on the status of open data and its future. In 2018 4th International Conference on Universal Village (UV), 1-4. https://doi.org/10.1109/ UV.2018.8642128.

Wihlborg, E., \& Engstrom, J. (2017). Bridging Digital Divides through Digital Media Buses An action research study on digital inclusion in Sweden (2017 7th International Conference for E-Democracy and Open Government).

Willis, K. S. (2019). Making a 'Place' for ICTs in rural communities the role of village halls in digital inclusion. In ACM International Conference Proceeding Series, 136-142. https://doi. org/10.1145/3328320.3328401.

Wixom, B. H., \& Watson, H. J. (2001). An empirical investigation of the factors affecting data warehousing success. MIS Quarterly, 25(1), 17. https://doi.org/10.2307/3250957.

Wongkhamdi, T., Cooharojananone, N., \& Khlaisang, J. (2017). The study of mobile learning readiness in rural area: Case of North-Eastern of Thailand. In 2017 International Symposium on Computers in Education (SIIE), 1-6. https://doi.org/10.1109/SIIE.2017.8259665.

World Bank. (2018). Rural Population. https://data.worldbank.org/indicator/SP.RUR.TOTL.ZS?locat ions=IN-ZG. Accessed 27 Jan 2019.

Wu, J.-H., \& Wang, Y.-M. (2006). Measuring KMS success: A respecification of the DeLone and McLean's model. Information \& Management, 43(6), 728-739. https://doi.org/10.1016/j. im.2006.05.002.

Yamakami, T. A. (2017). dimensional framework to evaluate coverage of IoT services in city platform as a service. In 2017 International Conference on Service Systems and Service Management, 16-18 June 2017 (pp. 1-5). https://doi.org/10.1109/ICSSSM.2017.7996134.

Yeh, H. (2017). The effects of successful ICT-based smart city services: From citizens' perspectives. [Article]. Government Information Quarterly, 34(3), 556-565. https://doi.org/10.1016/j. giq.2017.05.001.

Yonezawa, T., Galache, J. A., Gurgen, L., Matranga, I., Maeomichi, H., \& Shibuya, T. (2015). A citizencentric approach towards global-scale smart city platform (2015 International Conference on Recent Advances in Internet of Things).

Yu, J., Wen, Y. T., Jin, J., \& Zhang, Y. (2019). Towards a service-dominant platform for public value co-creation in a smart city: Evidence from two metropolitan cities in China. Technological Forecasting and Social Change, 142, 168-182. https://doi.org/10.1016/j.techfore.2018.11.017.

Yu, S. (2017). Design and implementation of internet financing platform for rural SMEs. In 2017 International Conference on Smart Grid and Electrical Automation (ICSGEA), 668-671. https:// doi.org/10.1109/ICSGEA.2017.53.

Zavratnik, V., Kos, A., \& Duh, E. S. (2018). Smart Villages: Comprehensive Review of Initiatives and Practices. Sustainability, 10(7), ARTN 255910.3390/su10072559.

Zhang, X. Q. (2016). The trends, promises and challenges of urbanisation in the world. Habitat International, 54, 241-252. https://doi.org/10.1016/j.habitatint.2015.11.018.

Zhu, K., Kraemer, K. L., \& Xu, S. (2006). The process of innovation assimilation by firms in different countries: A technology diffusion perspective on E-business. Management Science, 52(10), 15571576. https://doi.org/10.1287/mnsc.1050.0487.

Publisher's Note Springer Nature remains neutral with regard to jurisdictional claims in published maps and institutional affiliations. 